\title{
Blebs Promote Cell Survival by Assembling Oncogenic Signaling Hubs
}

\author{
Andrew D. Weems, Erik S. Welf, Meghan K. Driscoll, Hanieh Mazloom-Farsibaf, Bo-Jui Chang,
} Byron G. Weiss, Joseph Chi, Kevin M. Dean, Reto Fiolka, Gaudenz Danuser

\begin{abstract}
For most human cells, anchorage is a key necessity for survival. Cell-substrate adhesion activates diverse signaling pathways, without which cells undergo anoikis - a form of programmed cell death ${ }^{1}$. Acquisition of anoikis resistance is a pivotal step in cancer disease progression, as metastasizing cancer cells often lose firm attachment to surrounding tissue $e^{2-5}$. In these poorly attached states, cells often adopt rounded morphologies and form small hemispherical plasma membrane protrusions called blebs ${ }^{6-13}$. Bleb function has long been investigated in the context of amoeboid migration but is far less deeply examined in other scenarios ${ }^{14-19}$. Here we show by quantitative subcellular 3D imaging and manipulation of cell morphological states that blebbing triggers the formation of membrane-proximal signaling hubs that initiate signaling cascades leading to anoikis resistance. Specifically, in melanoma cells we discovered that blebbing generates plasma membrane contours that recruit curvature sensing septin proteins, which scaffold constitutively active mutant NRAS and effectors, driving the upregulation of ERK and PI3K signaling. Inhibition of blebs or septins has little effect on the survival of well-adhered cells, but in detached cells causes NRAS mislocalization, reduced MAPK and PI3K signaling, and ultimately, death. These data unveil an unanticipated morphological requirement for mutant NRAS to operate as an effective oncoprotein, suggesting novel clinical targets for the treatment of NRAS-driven melanoma. Furthermore, they define an unforeseen role for blebs as potent signaling organelles capable of integrating myriad cellular information flows into concerted signaling responses, in this case granting robust anoikis resistance.
\end{abstract}

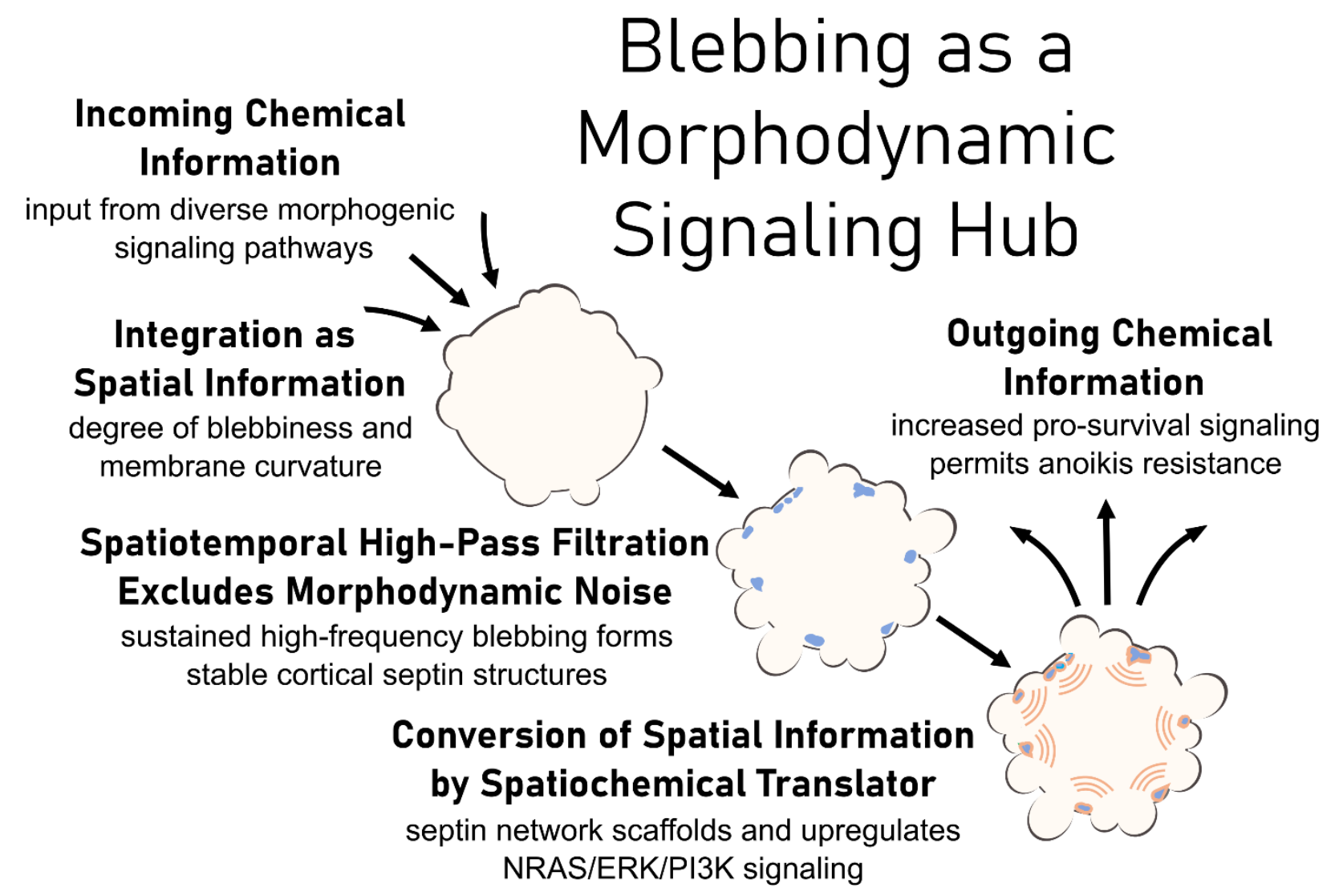




\section{Main}

Attachment-dependent survival is a fundamental aspect of metazoan cell physiology. Near universally, points of attachment - either to the extracellular matrix or other cells - generate pro-survival signals, often through the assembly of ultrastructural cellular architecture such as focal adhesions ${ }^{20,21}$ and adherens junctions ${ }^{22-24}$. These adhesive structures operate as signaling hubs by controlling local concentrations of signaling factors, protein scaffolds, and effector proteins ${ }^{25}$. If deprived of attachments, most cells will undergo a detachment-induced form of programmed cell death called anoikis ${ }^{1}$. Acquisition of molecular strategies that confer anoikis resistance is a critical step in oncogenesis ${ }^{2-4}$. Though many mechanisms of anoikis-resistance in cancer are known, understanding of this phenomenon is far from complete ${ }^{5}$.

Upon detachment, most metazoan cell types generally become rounded and display dynamic surface blebs ${ }^{7-13}$ (Movie 1). Blebs are hemispherical pressure-driven cellular protrusions that occur when portions of the cell membrane decouple from the actomyosin cortex ${ }^{6}$. Though blebbing famously occurs during apoptosis ${ }^{26-28}$, a second class of blebs are found in healthy cells with intact cortices ${ }^{6,28}$. These "dynamic blebs" are associated with cellular detachment, mitosis, and amoeboid motility. Detached untransformed cells maintain dynamic blebbing for only 1-2 hours, later undergoing anoikis if attachment is not re-established ${ }^{11,12,29}$. In contrast, cancer cells, such as those forming melanoma, are highly anoikis-resistant and able to indefinitely sustain rounded blebby morphologies in no- and low-attachment environments, often adopting this amoeboid phenotype both in vitro and in vivo - notably at the invasive front of tumors ${ }^{14-19}$. In parallel work, we found that primary and immortalized melanoma cells with high metastatic potential tend to be blebbier in mechanically compliant environments ${ }^{14}$. Similarly, blebbiness was recently shown to predict metastatic potential in prostate cancer ${ }^{30}$. Thus, cell blebbiness might be an indicator of disease aggressiveness for melanoma and possibly other cancers.

This correlative link between a blebby morphology and metastasis has up until now been attributed to the role of blebs in cell motility ${ }^{14-19}$. However, our recent work suggests signaling factors associated with cell survival tend to be concentrated in the vicinity of melanoma blebs, including KRAS and active PI3K ${ }^{14,31,32}$. Moreover, inhibition of blebbing causes a sharp reduction in local PI3K activity, raising the possibility that blebbing might directly enable this signaling ${ }^{14}$. Taken together, this information motivated an investigation of blebbing as a potential contributor to anoikis resistance in melanoma.

\section{Bleb inhibition disrupts anoikis resistance in melanoma cells}

We first inhibited bleb formation using wheat germ agglutinin (WGA), a lectin that reduces plasma membrane deformability by crosslinking components of the glycocalyx ${ }^{6}$. Using MV3 melanoma cells, we confirmed by morphological motif analysis ${ }^{31}$ WGA's effects as a dosage dependent inhibitor of bleb density on single cell surfaces (Fig 1A). To investigate putative bleb function as a driver of anchorage-independent cell survival we designed assays that consistently minimized both cell-substrate and cell-cell attachment over a period of 24 hours. We accomplished this goal by seeding cells at very low density (approx. $250 \mathrm{cells} / \mathrm{ml}$ ) in non-adherent culture dishes under constant gentle agitation. For controls we grew cells at identical concentrations in adherent variants of the same culture dishes. Together, this generated pairs of 'detached' and 'adhered' cell populations in paired same-day experiments.

Equipped with this assay, we performed WGA dose response survival analysis on three different melanoma cell lines: MV3 (NRAS(Q61R)-driven) ${ }^{33}$, A375 (BRAF(V600E)-driven) ${ }^{34}$, and M498 (BRAF(V600E)-driven primary cell line $)^{35}$. After 24 hours of bleb inhibition, detached MV3 cells showed high levels of cell death as measured by ethidium homodimer staining, but little to none when adhered (Fig 1B). Both adhered and detached M498 cells die upon WGA treatment, but detached cells experience significantly more death, both in aggregate and in individual matched experiments (Fig 1B, Fig S1). Compared to adherent MV3 cells, adherent M498 cells spread poorly and are easily detached with gentle pipetting, which potentially explains the increased susceptibility to 
bioRxiv preprint doi: https://doi.org/10.1101/2021.04.23.441200; this version posted April 24, 2021. The copyright holder for this preprint (which was not certified by peer review) is the author/funder, who has granted bioRxiv a license to display the preprint in perpetuity. It is made
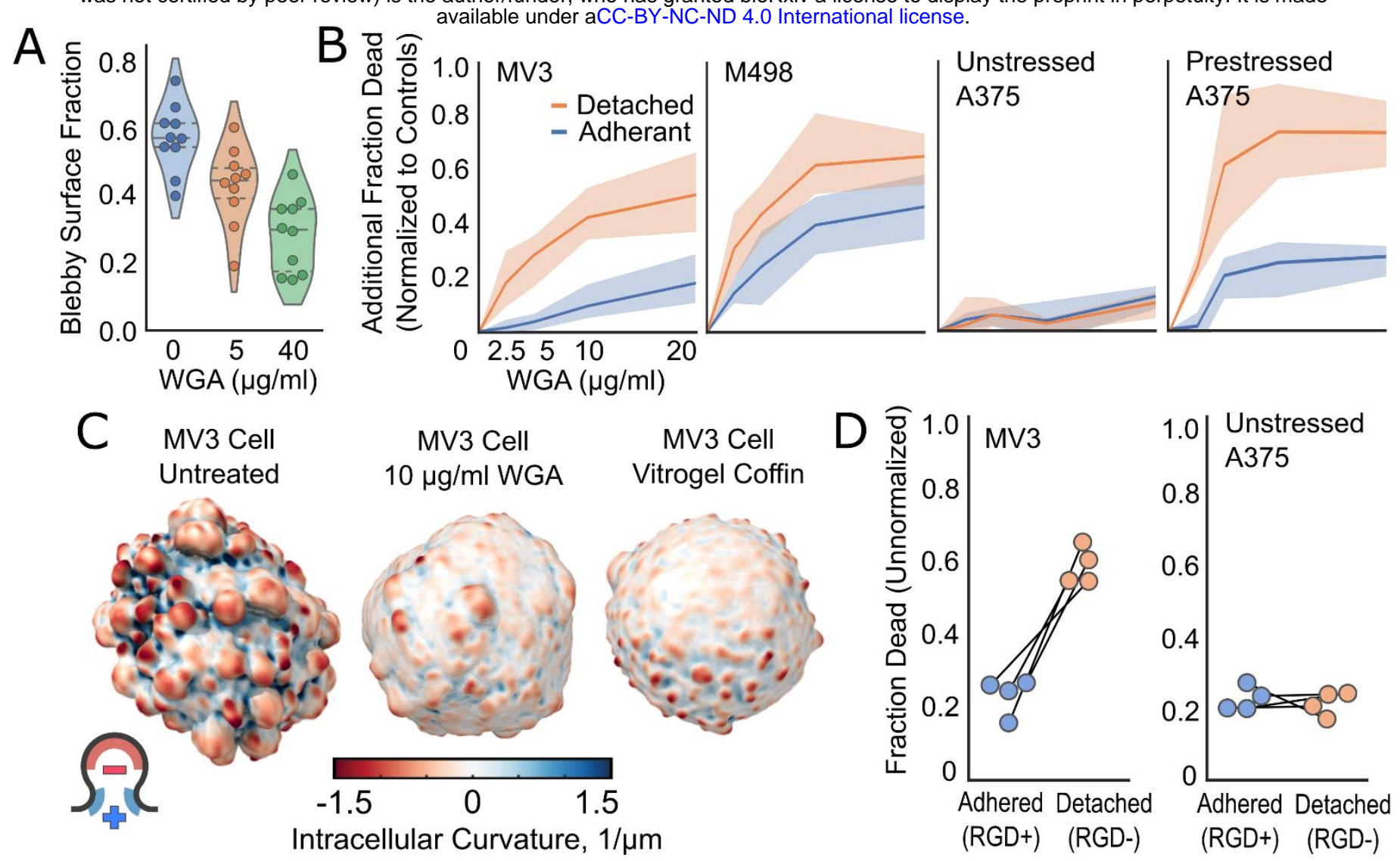

Figure 1: Bleb inhibition disrupts anoikis resistance in melanoma cells. (A) Fraction of cell surface comprised of blebs for MV3 cells treated with different concentrations of WGA. Dashed lines separate quartiles. Dots represent individual cells. (B) Cell death as a function of WGA treatment at different doses for adhered and detached melanoma cells. Cells grown for 24 hours and assayed for cell death using ethidium homodimer staining. All treatment groups grown and assayed in simultaneous paired experiments, which were performed three times for each cell line (See Fig. S1 for individual experiments). Replicate data were normalized by subtracting negative control values from each treatment group. Error bars represent 95\% confidence intervals. Sum cell counts for all replicates in ascending order of WGA dosage (see Table 1 for individual counts): MV3 Det. (470, 602, 479, 501, 562), MV3 Adh. $(688,569,597$, 426, 544), M498 Det. (290, 291, 159, 187, 133), M498 Adh. (405, 378, 347, 285, 316), Unstressed A375 Det. (867, 797, 670, 847, 679), Unstressed A375 Adh. (576, 453, 589, 578, 555), Prestressed A375 Det. (496, 493, 649, 317, 325), Prestressed A375 Adh. (495, 581, 448, 504, 475) (C) Cell surface renderings of representative cells showing mean intracellular curvature. (D) Cell death upon bleb inhibition using VitroGel coffins for adhered and detached melanoma cells. Cells grown for 24 hours in either integrin-binding VitroGel-RGD (adhered) or non-integrin-binding VitroGel (detached) and assayed for cell death using ethidium homodimer staining. Dots represent individual experiments. Sum cell counts for all replicates as follows, listed as they appear in the figure from left to right (see Table 1 for individual counts): 367, 389, 461, 509.

bleb inhibition in adherent conditions. A375 cells were unaffected by WGA treatment, regardless of their attachment state (Fig 1B), at first sight indicating that bleb inhibition is not a universal mechanism for establishing anoikis resistance. However, we observed that the confluency of A375 cells prior to these viability experiments influenced outcomes, with cells from more confluent culture conditions experiencing more death upon WGA treatment. To explore this, we allowed A375 cells to remain overconfluent for 48 hours (changing culture media daily) before performing viability experiments as before. We found that anoikis resistance in these "pre-stressed" A375 cells was strongly dependent upon blebbing, with an effect size even larger than that seen in MV3 cells (Fig 1B).

To ensure that the WGA-mediated disruption of anoikis resistance was due to bleb inhibition and not an offtarget effect of WGA, we performed a complementary experiment using VitroGel, an abiotic hydrogel used in cell culture ${ }^{36}$, to form bleb-restricting "coffins" around individual cells (Fig 1C). Coffins for "detached" cell growth were made using non-adherent VitroGel, while adherent coffins were made using VitroGel-RGD, which 
contained integrin-binding RGD domains that allow for cell adhesion. We performed these experiments on WGA-sensitive MV3 cells and WGA-insensitive A375 cells. As expected, far more MV3 cells died in nonadherent than in adherent VitroGel coffins, whereas A375 cells showed no difference in viability between the two conditions (Fig 1D). Taken together, these results indicate that dynamic blebbing contributes to anoikis resistance both in NRAS- and in BRAF-mutated melanoma, suggesting that this cell morphological program is a broadly adopted survival strategy in melanoma cells.

\section{Bleb-generated plasma membrane curvature drives the formation of cortical septin structures}

A notable feature of blebbing vs bleb-inhibited cells is the significant enrichment of micron-scale plasma membrane curvature. For an intracellular observer, curvature is negative/concave in the bleb proper (reaching values in the range of $\mathrm{K}=-1.5 \mu \mathrm{m}^{-1}$, where $\mathrm{K}$ represents the inverse of the radius of curvature) and positive/convex between the blebs (reaching values in the range of $k=1.5 \mu \mathrm{m}^{-1}$ ) (Fig 1C). Serendipitously, we discovered a marked recruitment of septins to locations in between densely packed blebs in MV3 cells, where positive intracellular curvature is greatly enriched. Indeed, in eukaryotic cells, members of the septin cytoskeletal family are the only proteins known to recognize positive micron-scale membrane curvature ${ }^{37,38}$. The notion that blebgenerated curvature could recruit septins to the plasma membrane upon cell detachment is supported by previous work ${ }^{39,40}$, though we found no reports of an explicit connection between bleb-related surface curvature and septin recruitment. Septins are known to scaffold and regulate factors from diverse signaling pathways ${ }^{41-44}$, including pro-survival pathways in cancer cells such as HIF-1 ${ }^{45-47}$, EGFR ${ }^{48}, \mathrm{MET}^{49,50}, \mathrm{JNK}^{51}$, and HER2 $2^{52}$. Therefore, we hypothesized that bleb-dependent anoikis resistance could be achieved through recruitment of curvature-sensitive septin proteins to the plasma membrane via bleb-generated curvature, where they promote pro-survival signaling.

To begin testing such an involvement of septins as translators of cell morphology into survival signaling, we performed mass spectrometry of MV3 cell lysate and found robust expression of several septin proteins (Table 2). Based on these results we decided to visualize septin structures in living cells by ectopic expression of mouse SEPT6-GFP ${ }^{39}$ and confirmed proper integration of the fluorescent probe into native septin complexes by pulldowns of mouse SEPT6-HALO. Mass spectrometry showed that all endogenous septins expressed in MV3 cells were pulled down by SEPT6-HALO, at levels 36x higher than in control pulldowns with no SEPT6-HALO expression (septins accounted for $0.22 \%$ of total protein abundance in the control and $8.1 \%$ in SEPT6-HALO pulldown), suggesting that the probe efficiently forms complexes with endogenous septins (Table 2).

By eye, septin structures are primarily found near blebby cell surface regions, while less blebby regions have few-to-none (Fig 2A, Movie 2). Computer vision analysis of multiple MV3 cells imaged at isotropic resolution to accurately measure surface curvature and signal intensity in three dimenions ${ }^{53}$ confirmed this observation, showing that bleb and septin polarity vectors are directionally correlated (Fig 2B). A global examination of these same cell surfaces showed that septins are enriched at positive curvatures above $\mathrm{k}=0.4 \mu \mathrm{m}^{-1}$ (septins have been previously shown to have high affinity for membrane with curvature values $\mathrm{K}>0.4 \mu \mathrm{m}^{-137,38}$ ) and drop sharply at lower curvatures (Fig 2C). Analysis of control and WGA-treated MV3 cells also confirmed that bleb inhibition reduces mean plasma membrane curvature above $\mathrm{K}=0.4 \mu \mathrm{m}^{-1}$ (Fig 2D). Examining septin structures relative to blebs showed that they tend to be found near bleb edges, with average intensity falling steeply as one moves towards the center of the bleb, and more slowly as one moves away from the bleb (Fig 2E). Predictably, curvature follows a similar pattern, tending to be highest at bleb edges (Fig 2E).

To more thoroughly test the notion that bleb formation as a morphodynamic process causally drives the assembly of septin structures, we perturbed blebbing by a variety of methods: In addition to WGA and VitroGel we used the ROCK inhibitor H1152 (reduces bleb formation by lowering intracellular pressure) and the Ezrin-inhibitor NSC668394 (causes large-scale membrane-cortex detachment and thus substitutes single-micron scale, dynamic blebs with large, stable blebs). Every approach had pronounced effects on septin localization, reducing cortical levels with remaining foci tending to be confined to high curvature areas (Fig 2 F). 

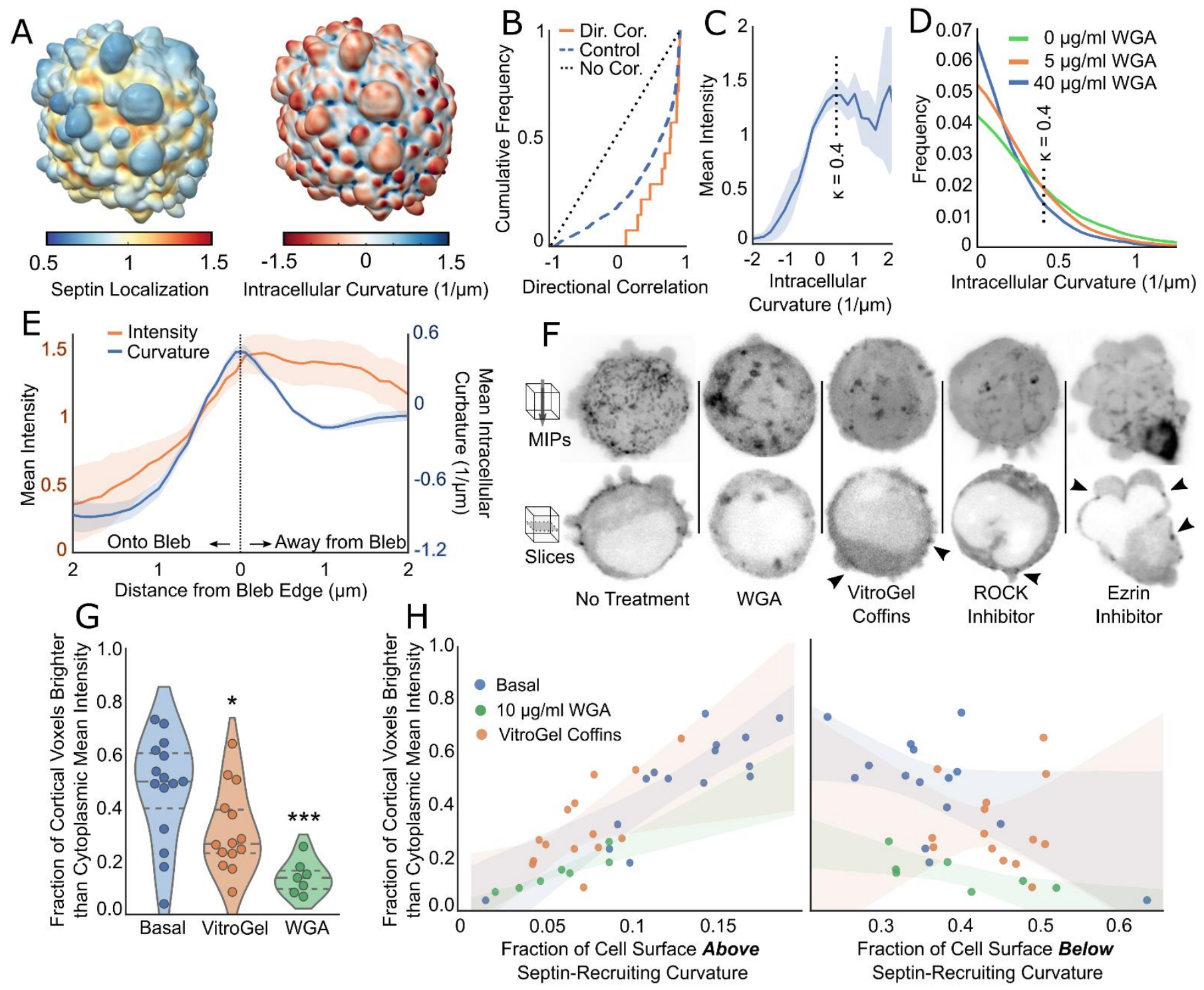

Figure 2: Bleb-generated plasma membrane curvature drives the assembly of cortical septin structures.

(A) Surface renderings of an MV3 cell showing either mean local intensity of septin signal or mean local intracellular curvature. Septin signal is murine SEPT6-GFP. Cells embedded in soft bovine collagen. (B) Directional correlation between blebs and septin localization in 14 MV3 cells. Cumulative correlative distribution is shown as orange solid line, randomized bleb localization control is shown as a dashed blue line, and zero correlation is shown as black dotted line. (C) Local mean intensity of septin signal as a function of local intracellular curvature, using same cells. (D) Probability distributions of mean local positive intracellular curvature for all cells in Fig. 1A.(E) Local mean septin intensity and intracellular curvature as a function of distance from bleb edges using same cells as Fig. 2B. (F) Septin localization in MV3 melanoma cells with diverse perturbations of bleb formation. Representative cells received treatment as follows: WGA (50 ug/ml), VitroGel, H1152 $(1 \mu \mathrm{M})$, NSC668394 $(10 \mu \mathrm{M})$. Maximum intensity projections and single optical slices of 0.16 micron thickness. Septin signal murine SEPT6-GFP. Arrowheads indicate septin accumulation in perturbed cells in regions with residual high-curvature. Cells embedded in soft bovine collagen. (G) Fraction of cortical voxels (within $0.96 \mu \mathrm{m}$ of surface) in basal and bleb-inhibited MV3 cells with septin intensity higher than cytoplasmic mean intensity. Dashed lines separate quartiles. Basal/VitroGel tested with two sample T-test using pooled variance $(p=0.013)$, normality tested with Shapiro-Wilk ( $p=0.2579 \& 0.31$ ), variance tested with two-tailed $F$ test $(p=0.448)$. Basal/WGA tested with Welch's T-test $(p<0.0001)$, normality tested with Shapiro-Wilk $(p=0.4539 \& 0.7941)$, variance tested with two-tailed F-test $(p=0.0114)(\mathbf{H})$ Same data as Fig. 2G expressed as a function of cell surface fraction possessing intracellular curvature either above (right, $\mathrm{k}>0.4 \mu \mathrm{m}^{-1}$ ) or below (left, $0>\mathrm{K}>0.4 \mu \mathrm{m}^{-1}$ ) septin recruiting threshold. 

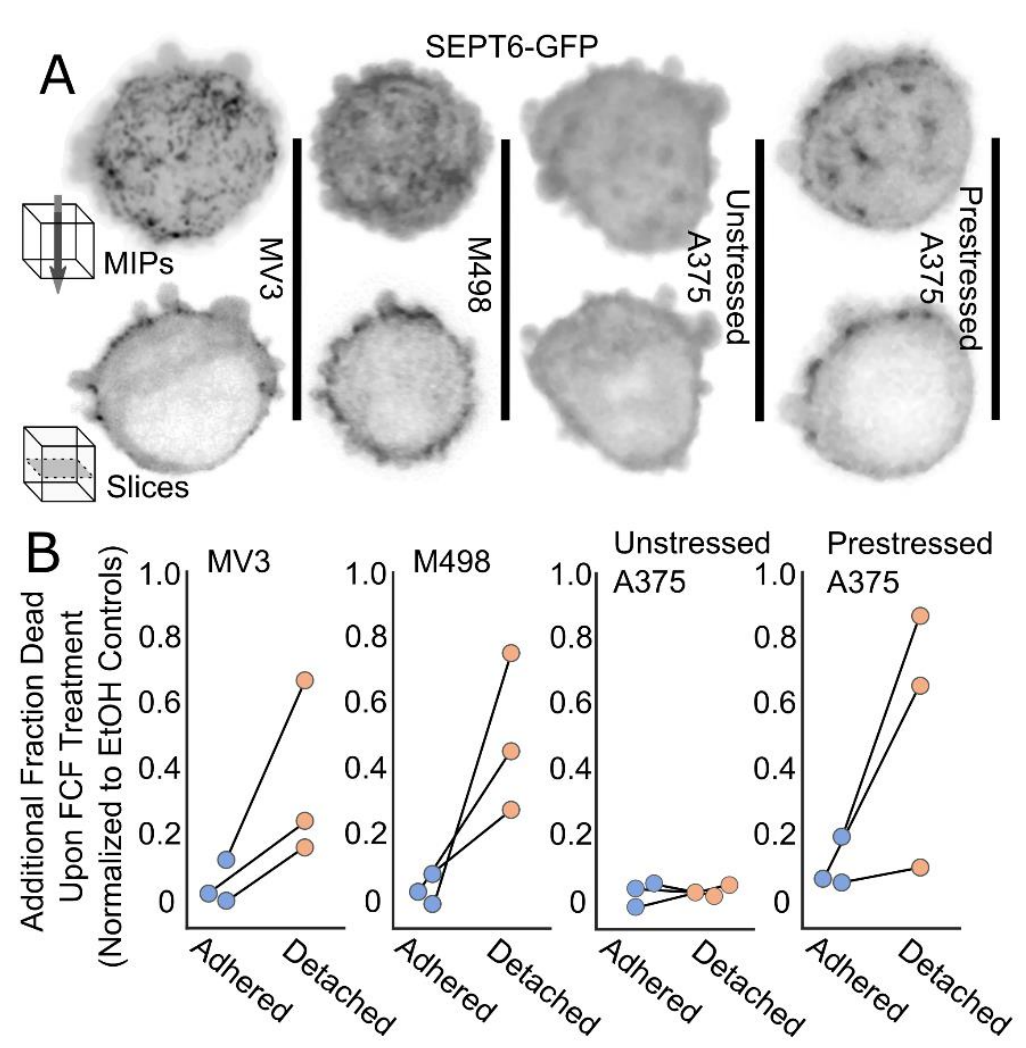

Figure 3: Septins are necessary for bleb-dependent anoikis resistance. (A) Septin localization in different melanoma cell lines. Maximum intensity projections (above) and single optical slices of 0.16 micron thickness (below) shown for representative cells. Septin signal is murine SEPT6-GFP. Cells embedded in soft bovine collagen. (B) Cell death upon septin inhibition with $50 \mu \mathrm{M} \mathrm{FCF}$ for adhered and detached melanoma cells. Cells grown as in Fig $1 \mathrm{~B}$ and treated with either FCF or EtOH control for 24 hours. Data were normalized by subtracting paired negative control values from each treatment group. Dots represent individual experiments. Sum cell counts for all replicates listed as they appear in the figure from left to right, with control counts in parentheses (see Table 1 for individual counts): 440(470), 644(688), 298(290), 338(405), 823(867), 562(576), 418(541), 169(205).
We then quantified the cortical septin levels as the surface fraction of cortical voxels (voxels $<0.96 \mu \mathrm{m}$ from the surface) above mean cytoplasmic SEPT6GFP intensity. Both WGA and VitroGel treatments significantly reduced cortical septin levels relative control conditions, as expected (Fig 2G). Moreover, in all three experimental conditions, we found a strong linear relationship at the single cell level between the surface fraction of predicted septin-recruiting curvature $\left(\kappa \geq 0.4 \mu \mathrm{m}^{-1}\right)$ and cortical septin levels (Fig $\mathbf{2 H}$ ). In contrast, expressing these same data as a function of surface fraction with positive curvature below the septin-recruiting threshold $\left(0 \mu \mathrm{m}^{-1} \geq \mathrm{K} \geq 0.4 \mu \mathrm{m}^{-1}\right)$ failed to show a similar relationship (Fig $2 \mathbf{H}$ ). Thus, septin levels at the cortex universally correlate with the presence of septin-recruiting plasma membrane curvature, and experimental conditions which reduce such curvature, like those inhibiting bleb formation, abrogate septin recruitment. This adds another case to a growing series of examples of cell shape dictating subcellular molecular organization ${ }^{54}$.

\section{Septins are necessary for bleb-dependent anoikis resistance}

Given the causal relation between bleb formation and septin localization, we sought to determine whether a link existed between such cortical septin structures and bleb-dependent anoikis resistance. Live cell imaging of poorly adhered cells embedded in soft collagen showed that MV3, M498, and prestressed A375 cells possess extensive cortical septin structures that seem to be spatially associated with blebs (Fig 3A). In contrast, nonstressed A375 cells displayed no septin

enrichment at the cortex despite robust bleb formation. We repeated pull-down mass spectrometry experiments in non-stressed A375 cells and confirmed that the apparent lack of cortical septins was not due to a failure of the probe to integrate into native septin structures (Table 2). Thus, the cell lines whose anoikis resistance is blebdependent possess bleb-associated septin structures, while the bleb-independent cell line has none.

To further test the conclusion that bleb-associated septin structures regulate survival signaling, we measured the anoikis-resistance of these four cell lines when treated with the septin inhibitor forchlorfenuron (FCF $)^{55}$. As predicted, FCF greatly disrupted anoikis resistance for MV3, M498, and pre-stressed A375 cells while having no appreciable effect on non-stressed A375, mirroring bleb inhibition results (Fig 3B). Taken together, these data suggest that the mechanism allowing blebs to confer anoikis resistance upon melanoma cells depends on blebadjacent cortical septin structures. 


\section{Bleb-associated cortical septins interact with NRAS and MAPK effector proteins}

We hypothesized that bleb-induced septin structures promote anoikis resistance as a signaling scaffold that amplifies survival signals. To identify signaling candidates we performed BioID proximity labeling ${ }^{56}$ using SEPT6 as bait. We obtained 321 septin-interacting proteins (full results in Supplemental Data 1), among them three plasma membrane-localized components of major signal transduction pathways: Notch, CD44, and NRAS. As Notch and CD44 are canonically juxtacrine, we focused on NRAS as a more likely candidate for survival signaling in detached cells. We also found Prohibitin ${ }^{57}, 14-3-3 \zeta^{58}$, and Nucleolin ${ }^{59,60}$ among the BiolD prey, which are all potent effectors of the RAS/RAF/MEK/ERK and RAS/PI3K/AKT pathways. Importantly, reexamination of our previous pulldown data revealed that NRAS interacted with SEPT6 in MV3 cells, but not in unstressed A375, indicating that the NRAS/septin interaction depends on the assembly of bleb-nucleated cortical structures. NRAS was also an especially intriguing candidate as MV3 cells harbor a constitutively active Q61R mutant, leaving open the possibility that suspended NRAS-driven melanoma cells harness their mutational profile via an acute morphological program to empower oncogenic signaling through the RAS/RAF/MEK/ERK and RAS/PI3K/AKT axes.

To support these proteomic results, we performed live cell imaging studies to confirm that the SEPT6/NRAS interaction occurs in rounded, detached cells. As expected, ectopically expressed NRAS-GFP co-localized with cortical septins in bright patches (Fig 4A). Moreover, perturbation of septin structures using FCF significantly reduced enrichment of NRAS near the cell surface (Fig 4B). To confirm that these results were not due to an off-target effect of FCF, we engineered a dominant negative mutant of human SEPT2, SEPT2 $(33-306)^{61,62}$, that eliminated cortical septin structures upon expression (Fig S2). As predicted, SEPT2(33-306) expression significantly reduced cortical enrichment of NRAS. To further investigate how septin inhibition affects NRAS localization, we employed Optimal Transport analyses borrowed from computer graphics to calculate the Earth Mover's Distance (EMD) ${ }^{63,64}$ as a metric for the spatial heterogeneity of the NRAS signal at the cell surface compared to homogenous distributions of the same amount of signal on the same surface. The results followed our predictions: Septin-inhibited cells tend to produce lower EMD values (suggesting diffuse signal distributions) than unperturbed cells (Fig 4C). Taken together, these data strongly suggest that cortical septin structures bind and scaffold NRAS, affecting its spatial distribution near the surface and increasing its cortical concentration.

\section{Septins promote NRAS/ERK and NRAS/PI3K survival signaling}

To determine whether NRAS signaling is important for anoikis resistance in MV3 cells, we overexpressed NRAS(S17N), a dominant negative mutant known to disrupt NRAS signaling ${ }^{65}$. Like bleb and septin inhibition, perturbation of NRAS had little effect on the survival of adhered cells, but consistently increased death in detached cells (Fig 4D).

To determine whether septin organization of NRAS and its effectors affects downstream MAPK signaling, we used the ERK-nKTR nuclear translocation biosensor ${ }^{66}$, which allowed us to monitor the signaling states of individual cells. Because the prevention of cell-cell adhesion requires maintaining ultra-low cell densities, we opted to use quantitative live cell microscopy rather than Western blotting. After 3 hours of septin inhibition with FCF, we found adhered cells to have no difference in ERK signaling compared to controls, while ERK activation was significantly reduced in detached cells (Fig 4E). Similarly, we measured the effect of 3 hours of detachment vs. adhesion on unperturbed MV3 cells, MV3 cells expressing the dominant negative SEPT2(33-306) mutant, and MV3 cells grown in Vitrogel coffins. Detachment of uninhibited cells caused little change in ERK activation, while septin and bleb inhibition in detached cells drastically decreased ERK activation (Fig 4F). Thus, both septins and blebs are necessary for maintaining ERK signaling in detached, but not adhered, MV3 melanoma cells.

Finally, because PI3K signaling can be driven by NRAS, and our previous work has shown that bleb inhibition alters PI3K activity ${ }^{14}$, we also tested whether septin-mediated cortical scaffolding of NRAS(Q61R) would drive PI3K signaling in detached MV3 cells - thereby activating a second survival pathway. Using the PI3K activity 

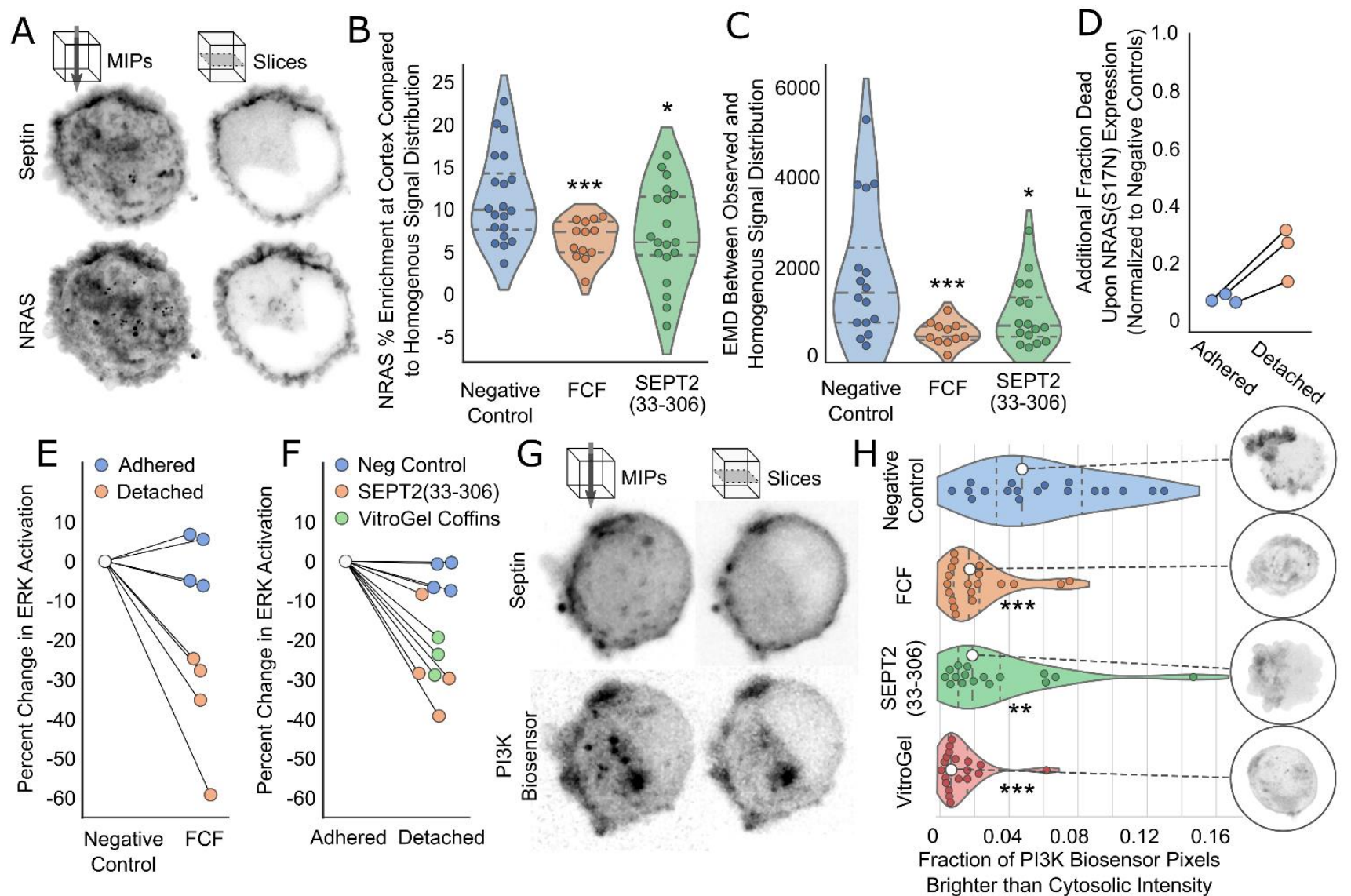

Figure 4: Septins scaffold NRAS, promoting NRAS/MAPK and NRAS/PI3K survival signaling. (A)

Representative MV3 cell showing colocalization between SEPT6-HALO-JF549 and NRAS-GFP. Maximum intensity projections and single optical slices of 0.16 micron thickness. Cells embedded in soft bovine collagen. (B) Observed NRAS-GFP \% enrichment at the cortex (voxels within $0.96 \mu \mathrm{m}$ of surface) of individual unperturbed and septininhibited MV3 cells. Basal/FCF tested with Welch's T-test $(p<0.0001)$, normality tested with Shapiro-Wilk $(p=0.2191 \&$ $0.2198)$, variance tested with two-tailed $F$ test $(p=0.0054)$. Basal/SEPT2(33-306) tested with two sample T-test using pooled variance $(p=0.0101)$, normality tested with Shapiro-Wilk ( $p=0.2191 \& 0.7246)$, variance tested with two-tailed $F$ test $(p=0.768)$.Dashed lines separate quartiles. (C) Earth Mover's Distance (EMD) between observed NRAS-GFP and homogenous distribution of equivalent signal as measured for each unperturbed or septin-inhibited MV3 cell. Control/FCF tested with Mann-Whitney U test ( $p=0.0007)$, normality tested with Shapiro-Wilk $(p=0.0198 \& 0.9537)$. Control/SEPT2(33-306) Mann-Whitney U test ( $p=0.0213)$, normality tested with Shapiro-Wilk ( $p=0.0198 \& 0.0265)$. (D) Cell death upon expression of dominant negative NRAS(S17N) for adhered and detached MV3 cells. Cells grown as in Fig 1B for 24 hours. Data were normalized by subtracting paired negative control values from each treatment group. Dots represent individual experiments. Sum cell counts for all replicates, listed as they appear in the figure from left to right, with control counts in parentheses (see Table 1 for individual counts): 1105(1039), 799(734). (E) Effect of septin inhibition upon ERK activation levels in adhered and detached MV3 cells. Percent change in ERK activation between unperturbed and septin inhibited MV3 cells measured by ERK-nKTR-GFP biosensor. Cells grown as in Fig 1B for 12 hours. Dots represent individual experiments. Sum cell counts for all replicates as follows (see Table 1 for individual counts): Adh. Control 234, Adh. FCF 236, Det. Control 405, Det. FCF 339. (F) Effect of detachment upon ERK activation levels in unperturbed, septin-inhibited, and bleb-inhibited MV3 cells. Percent change in ERK activation between attached and detached MV3 cells measured by ERK-nKTR-GFP biosensor. Cells grown as in Fig 1B for 12 hours. Dots represent individual experiments. Sum cell counts for all replicates as follows (see Table 1 for individual counts): Adh. Control 276, Det. Control 294, Adh. SEPT2(33-306) 274, Det. SEPT2(33306) 232, Adh. VitroGel 240, Det. VitroGel 205. (G) Representative MV3 cell showing colocalization between SEPT6GFP and Akt-PH-SNAP-TMR-Star. Maximum intensity projections and single optical slices of 0.16 micron thickness. Cells embedded in soft bovine collagen. (H) Effect of septin or bleb inhibition upon PI3K activity in individual MV3 cells. PI3K activity measured with the PI3K biosensor Akt-PH-GFP and expressed as fraction of pixels brighter than cytosolic intensity in normalized sum intensity projections. 


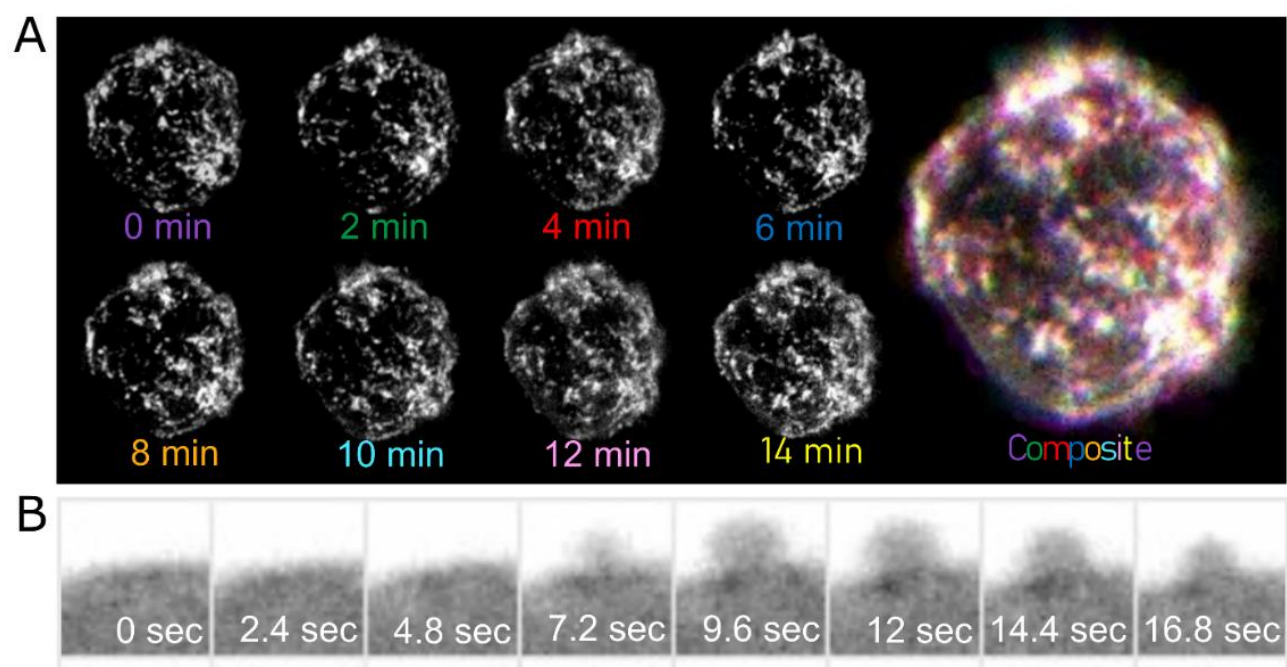

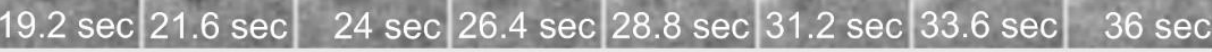

Figure 5: Short-lived blebbing events lead to long-lived cortical septin structures. (A) Timelapse showing changes in gross septin localization over 14 minutes in maximum intensity projections of a representative MV3 cell. Individual timepoints shown in grayscale on left and indicated pseudocolor in composite on right. Septin signal is murine SEPT6-GFP. Cell embedded in soft bovine collagen. (B) Timelapse showing septin accumulation during an individual blebbing event. Single optical section of $0.16 \mu \mathrm{m}$ thickness. Septin signal is murine SEPT6-GFP. Cell embedded in soft bovine collagen. biosensor Akt-PH-GFP50, we found that high PI3K activity co-localizes with both septins and NRAS in rounded, poorly-adhered MV3 cells embedded in soft collagen, in support of septin-scaffolded NRAS signaling through PI3K (Fig 4G, Fig S3). We then performed septin inhibition, either through FCF treatment or expression of SEPT2(33-306), and measured the resulting effect upon PI3K signaling. In both cases, PI3K activity fell significantly (Fig $\mathbf{4 H}$ ). Similarly, bleb inhibition with VitroGel coffins greatly depleted PI3K activity, in agreement with our previously published results showing the same effect upon bleb inhibition by WGA ${ }^{14}$ (Fig 4H). Altogether, these data show that bleb and septin inhibition specifically reduces both ERK and PI3K activation levels in detached MV3 melanoma cells, supporting the idea that bleb-nucleated cortical septin structures promote anoikis resistance through the scaffolding and upregulation of NRAS/RAF/MEK/ERK and NRAS/PI3K/AKT signaling.

\section{Cortical septin structures are formed by repeated bleb-driven curvature events}

Though bleb lifetimes were typically $<60$ seconds, we found cortical septin structures to be relatively stable over a period of 14 minutes (Fig 5A). This posed the question of how a relatively brief morphodynamic event can determine molecular architecture on longer time scales. To address this we turned to high-speed time-lapse light-sheet microscopy. This approach revealed that while "pulses" of septin accumulation can be seen at the curvy bases of blebs, they fade quickly once the bleb is resolved and curvature subsides (Fig 5B, Movie 3). Cytosolic septins predominantly exist as small complexes that preferentially bind to curved membrane, though they quickly detach unless membrane binding is stabilized by local concentration becoming high enough to promote polymerization $37,38,67$. We therefore hypothesized that stable cortical septin structures are formed not by individual, but iterative bleb-driven curvature events that result in local septin levels surpassing the threshold of polymerization and enabling higher-order structure formation. In agreement with this model, our high-speed timelapse data showed stable septin structures emerging only when several pulses occurred in close proximity, resulting in their coalescence into bright, long-lived structures whose intensity does not seem to rely on local curvature profiles (Movie 4). This suggests that septins act as a discrete time integrator of a sustained and spatially persistent dynamic bleb formation process, while also efficiently eliminating the effects of random and isolated morphological events as a discrete spatiotemporal high-pass filter. Thus, septins are ideally suited to translate significant cell morphological cues into cellular signals. 


\section{Discussion}

Bleb formation has long been recognized as a morphological program associated with melanoma cells and metastasis. While this program has been primarily interpreted as a means of amoeboid migration, our study now shows that dynamic blebbing prompts the construction of septin signaling hubs that substitute for the loss of anchorage-dependent signaling activity upon substrate detachment. Once constructed, such signaling would provide improved survival for cancer cells traveling through low-adhesion environments such as blood and lymph. While it is unknown whether other cell types might employ this bleb/septin signaling paradigm, the widely observed tendency of metazoan cells to bleb upon detachment leads one to wonder whether this strategy might be more broadly distributed and ancient than human melanoma. Future study will be needed to answer the many questions prompted by such a possibility.

Septins are highly versatile protein scaffolds that organize and regulate diverse signaling pathways across multiple kingdoms of life ${ }^{41-44}$. While we think our findings support the hypothesis that bleb-associated septins specifically drive anoikis-resistance in melanoma cells via scaffolding of NRAS and downstream pathways, we see no reason to exclude other signaling pathways following the same paradigm. Indeed, in our proteomic results septins interact with both CD44 and Notch which, though they are canonically involved in juxtacrine signaling, have both demonstrated the ability to transduce signal in the absence of activation by neighboring cells or $\mathrm{ECM}^{68,69}$. Similarly, dynamic blebbing does not occur only in human cells challenged with anoikis, but has also been observed in stem cells $\mathbf{s}^{70-73}$, migratory cells $\mathbf{s}^{14,74,75}$, and cells undergoing mitosis ${ }^{76}$, not to mention a wide variety of cancer cells ${ }^{77}$. With this in mind, we expect that if future work finds this bleb/septin signaling modality to be important in other cell types, it will not be exclusively RAS-driven nor survival-oriented, but rather reflect the diversity of cell types and behaviors with which it is associated.

Because MV3 cells harbor the NRAS(Q61R) oncogene classically thought to drive constitutive upregulation of these pathways, our results suggest that this activating mutation is not always sufficient to maintain downstream signaling at levels that guarantee cell viability. Previous work has shown that wildtype and mutant RAS function is regulated through the formation of nanoclusters, small regions of extremely high RAS protein density ${ }^{78,79}$. This suggests that septins might serve to modulate local NRAS concentration, thereby affecting downstream signal amplitude. It is also likely that septin scaffolding amplifies downstream signals by influencing NRAS interactions with its effectors, such as those found in our proteomic studies. In either case, this finding highlights the functional gap between the genomic condition of possessing an oncogene, and the cellular condition of experiencing penetrant oncogenic signaling. Moreover, it suggests the consideration of septins as a potential therapeutic target for NRAS-mutant melanoma, a disease currently associated with poor prognoses and limited therapeutic options due to the lack of targeted drugs ${ }^{80}$.

In the bleb/septin/NRAS signaling pathway described here, information flow is transduced from chemical (morphogenic signaling), to spatial (blebbiness), and back to chemical (survival signaling), with septins acting not only as a spatiochemical translator, but also serving as a high-pass filter and discrete time integrator of pulsatile spatial information. While control of morphology is often thought of as a terminal objective of cell signaling, consideration of cellular morphodynamics as an upstream input to signal transduction defines a new paradigm. Such morphological cues would not only act as potent drivers of signaling, but also as integrators of cell-autonomous and cell external information flows. For example, dynamic blebbing is typified by low Rac1 activity, high Rho/Rock activity, low ERM engagement, high actomyosin contraction, low glycocalyx density, and low attachment ${ }^{75,81}$. All this information is integrated into a state that is interpretable as a single signal transduction node by septins, which can then be activated to form versatile signaling hubs capable of regulating a myriad of different signaling pathways. 


\section{Methods}

\section{Cell Culture and Reagents}

MV3 cells were obtained from Peter Friedl (MD Anderson Cancer Center, Houston TX). A375 cells (ATCC® CRL1619) were acquired from ATCC. M498 cells were acquired from Sean Morrison (UT Southwestern, Dallas, TX). MV3, A375, and M498 cells were cultured in DMEM (Gibco) supplemented with $10 \%$ fetal bovine serum (FBS; ThermoFisher) at $37^{\circ} \mathrm{C}$ and $5 \% \mathrm{CO} 2$.

\section{Inhibitors}

Wheat Germ Agglutinin (WGA) was purchased from Sigma (product \# L9640). Forchlorfenuron (FCF) was purchased from Sigma (product \# C2791). VitroGel and VitroGel-RGD were purchased from TheWell Bioscience (sku \#s TWG001 and TWG002). H1152 was purchased from Tocris (catalogue \# 2414). NSC6683394 was purchased from Sigma (product \# 341216).

\section{Recombinant DNA Constructs}

Mouse SEPT6-GFP construct was purchased from Addgene (Addgene plasmid\# 38296) and was cloned into the pLVX-IRES-puro vector (Clontech). The GFP-AktPH construct was obtained from the laboratory of Jason Haugh (North Carolina State University, Raleigh NC) (Haugh et al., 2000) and cloned into the pLVX-IRES-puro vector (Clontech). The GFP-tractin construct was a gift from Dyche Mullins (Addgene plasmid \# 58473) and was cloned into the pLVX-IRES-puro vector (Clontech). The BioID2 construct was obtained from Addgene (Addgene plasmid \# 74223) and cloned onto the N-terminus of SEPT6 from SEPT6-GFP-pLVX-IRES-puro, replacing eGFP but maintaining the same 22 amino acid linker. SEPT6-HALO was made by cloning the HALO tag from pFN21K (Promega cat\# G2821) onto the N-terminus of SEPT6 from SEPT6-GFP-pLVX-IRES-puro, replacing eGFP but maintaining the same 22 amino acid linker. ERK-nKTR-GFP was purchased from Addgene (Addgene plasmid \# 59150). C-terminally mGFP-tagged human NRAS in pLenti-C-mGFP was purchased from OriGene (OriGene cat\# RC202681L2). C-terminal mGFP was removed and eGFP tag was cloned onto the Nterminus after aberrant localization was observed upon expression in MV3 cells (presumably due to steric inhibition of C-terminal palmitoylation and farnesylation domains by the C-terminal mGFP tag). NRAS(S17N) mutant was generated by cloning the S17N mutation into untagged NRAS-pLenti construct using HiFi assembly. pBOB-Septin2-GFP was purchased from Addgene (Addgene plasmid \# 118734), aa 1-32 and 307 361 were removed via PCR to create SEPT2(33-306), and the construct was cloned into pLVX-IRES-puro vector (Clontech). H2B-mCherry was obtained from Addgene (Addgene \#89766). Cells expressing lentiviral vectors were created by following the manufacturer's instructions for virus preparation and cell infection (Clontech). Cells were selected for expression by treatment with puromycin, G418, or by using fluorescence activated cell sorting.

\section{Detached/Adhered Cell Culture}

Cells were grown to $70-80 \%$ confluency, trypsinized for 3 minutes, resuspended at approximately $250 \mathrm{cells} / \mathrm{ml}$ (measured by eye using light microscopy) in DMEM (Gibco) supplemented with $10 \%$ fetal bovine serum (FBS; ThermoFisher) and detached from one another by repeated pipetting. Drug treatments or solvent-only controls were added to suspensions if appropriate to the experiment, and then immediately transferred to both an uncoated (for detached cells) and ibiTreated (for adhered cells) 8-well ibidi $\mu$-slide (ibidi cat\# 80821 and 80826 ) 
at $200 \mu \mathrm{l} /$ well. Both slides were stored at $37^{\circ} \mathrm{C}$ and $5 \% \mathrm{CO} 2$ for either $24 \mathrm{hrs}$ for viability assays or $3 \mathrm{hrs}$ for ERK activity assays. Uncoated slides (detached) were nutated at $20 \mathrm{rpm}$ during this time. At the end of this period detached cells were examined by microscopy to confirm that cells did not aggregate - if aggregates were found (results from protocol optimization show this was most commonly caused by wells being seeded at too high a cell density), the experiment was discarded and repeated.

\section{Cells Embedded in 3D Collagen}

Collagen gels were created by mixing bovine collagen I (Advanced Biomatrix 5005 and 5026) with concentrated phosphate buffered saline (PBS) and water for a final concentration of $2 \mathrm{mg} / \mathrm{mL}$ collagen. This collagen solution was then brought to $\mathrm{pH} 7$ with $1 \mathrm{~N} \mathrm{NaOH}$ and mixed with cells just prior to incubation at $37^{\circ} \mathrm{C}$ to induce collagen polymerization. Cells were suspended using trypsin/EDTA (Gibco), centrifuged to remove media, and then mixed with collagen just prior to incubation at $37^{\circ} \mathrm{C}$ to initiate collagen polymerization. To image collagen fibers, a small amount of collagen was conjugated directly to AlexaFluor 568 dye and mixed with the collagen sample just prior to polymerization. Poorly-adhered cells were enriched in samples by visualizing immediately upon collagen polymerization, and visually selected for those displaying rounded, blebby morphologies.

\section{Cells Grown in VitroGel Coffins}

VitroGel coffins were prepared by embedding MV3 or A375 cells in VitroGel 3D or RGD at 1:1 dilution according to manufacturer's instructions (TheWell Biosciences, sku \# TWG001). Briefly, cells were grown to $70-80 \%$ confluency, trypsinized, and diluted to approximately 500 cells/ml in in DMEM (Gibco) supplemented with $10 \%$ fetal bovine serum (FBS; ThermoFisher) and detached from one another by repeated pipetting. A 1:1 solution of VitroGel and VitroGel Dilution Solution was made, and added to cell suspension at a ratio of 4:1 (VitroGel:cells) using gentle pipetting until well-mixed (with care taken not to form bubbles). Cell/VitroGel solution was transferred to an 8-well uncoated ibidi $\mu$-slide (ibidi cat\# 80821) at $100 \mu \mathrm{l} /$ well, spread over the bottom of wells with a pipette tip, and allowed to polymerize at room temperature for 15 minutes. The remainder of the well was then filled with $10 \%$ FBS DMEM and slide was stored at $37^{\circ} \mathrm{C}$ and $5 \% \mathrm{CO} 2$ for either $24 \mathrm{hrs}$ for viability assays, $3 \mathrm{hrs}$ for ERK activity assays, or $1 \mathrm{hr}$ for visualization of septins / PI3K activity.

\section{Viability and ERK Activity Cell Counting Assays}

Viability and ERK activity assays were analyzed using live-cell fluorescent and phase-contrast microscopy, performed on a Nikon Ti microscope equipped with an environmental chamber held at $37^{\circ} \mathrm{C}$ and $5 \% \mathrm{CO} 2$ at 20x magnification. For viability assays, cells were stained with ethidium homodimer-1 (Invitrogen cat \# E1169) at $4 \mu \mathrm{M}$ and Hoechst (ThermoFisher cat \# H3570) at $10 \mu \mathrm{g} / \mathrm{ml}$ for 15 minutes before imaging. Live and dead cells (as identified by significant cellular ethidium signal) were counted using the Cell Counter ImageJ plugin. For ERK activity assays, live cells carrying ERK-nKTR-GFP and H2B-mCherry were imaged after 3 hours of experimental conditions and high / low ERK activity cells were counted with Cell Counter ImageJ plugin. Cells in which nuclear GFP signals were by eye higher than cytoplasmic signal ("brighter" nucleus visible within "darker" cytoplasm) were labelled ERK low, while cytoplasmic signals equal to or higher than nuclear signal (nucleus indistinguishable from cytoplasm or "darker" nucleus within "brighter" cytoplasm) were labelled ERK high. To control for unconscious bias in making this determination, the identity of all ERK experimental groups were blinded from the analyst. 


\section{Proteomics}

MV3, MV3 expressing SEPT6-HALO, A375, and A375 expressing SEPT-Halo cells were each plated in 150 $\mathrm{mm}$ dishes at approximately $7.5 \times 10^{6}$ cells per dish and grown to 70-80\% confluency. Pulldowns were performed per manufacturer's instructions (Promega, G6504). Cells were washed and harvested in ice cold PBS. Cells were pelleted at $2000 \mathrm{RCF}$ for 10 minutes at $4^{\circ} \mathrm{C}$. Pellets were stored at $-80^{\circ} \mathrm{C}$ for 72 hours. Pellets were then thawed at room temperature, lysed in Mammalian Lysis Buffer supplemented with Protease Inhibitor cocktail (Promega). The lysate was homogenized with a 27G syringe and centrifuged at 14,000 RCF for 5 min at $4^{\circ} \mathrm{C}$. The supernatant was diluted in TBS and incubated with pre-equilibrated HaloLink Resin (Promega) at room temperature with rotation for 15 minutes. Resin was then washed 4 times with Resin Wash Buffer (Promega). Complexed proteins were eluted in SDS Elution Buffer (Promega) for 30 minutes at room temperature. Eluted samples and whole cell lysate controls were loaded and run on a 10\% Mini-PROTEAN TGX protein gel (Biorad), visualized with AcquaStain (Bulldog Bio), excised, and analyzed with an Orbitrap Fusion Lumos using reverse-phase LC-MS/MS. MS data were analyzed using Proteome Discoverer 2.2 and searched using the human protein database from Uniprot.

For BioID proximity labeling, approximately $4 \times 10^{7}$ cells were incubated in DMEM (Gibco) supplemented with $10 \%$ fetal bovine serum (FBS; ThermoFisher) and $50 \mu \mathrm{m}$ Biotin for 16 hours at $37^{\circ} \mathrm{C}$ and $5 \% \mathrm{CO} 2$. Cells were washed twice in 1x PBS and lysed with 1:1 dilution of 2xJS buffer (100mM HEPES ph7.5, 300mM NaCl, $10 \mathrm{mM}$ EGTA, 3mM MgCl2, 2\% glycerol, 2\% triton-100) containing HALT phosphatase-protease cocktail (ThermoFisher \#23225). Cells were collected using a cell scraper, Triton X-100 was added to $2 \%$, and the resulting mixture was put on ice and sonicated. An equal volume of chilled lysis buffer was added and the mixture was sonicated again before centrifugation at 16,500 RCF for 10 minutes. The supernatant was collected and incubated overnight with Dynabeads (ThermoFisher \#65602) at $4^{\circ} \mathrm{C}$. Beads were magnetically collected and supernatant was removed. Beads were washed $4 \mathrm{x}$ with $50 \mathrm{nM}$ Tris- $\mathrm{Cl}, \mathrm{pH} 7.4$ with $8 \mathrm{M}$ Urea and supernatant was removed completely. Beads were resuspended in Laemmli buffer and biotinylated proteins were eluted by boiling for 5 minutes. Supernatant was loaded and run on a $10 \%$ Mini-PROTEAN TGX protein gel (Biorad), visualized with AcquaStain (Bulldog Bio), excised, and analyzed with an Orbitrap Fusion Lumos using reverse-phase LC-MS/MS. MS data were analyzed using Proteome Discoverer 2.2 and searched using the human protein database from Uniprot.

\section{D Light-Sheet Imaging}

3D samples were imaged using two variants of axially-swept light-sheet microscopy ${ }^{82,83}$, the first of which provides sub-400 nm isotropic raw resolution, and the second near-isotropic at $~ 400 \times 400 \times 450 \mathrm{~nm}$, uniformly maintained throughout large fields of view of $\sim 100 \times 100 \times 100$ microns. The first variant is equipped with 40X NA 0.8 Nikon illumination and detection objectives, and the second is equipped with a NA 0.67 Special Optics illumination objective and a 25X NA 1.1 Nikon detection objective. For very fast imaging, where aberration-free remote focusing of the illumination light-sheet becomes rate-limiting, these microscopes could also be operated in traditional light-sheet microscopy mode. Here, the numerical aperture of the illumination beam was reduced to cover a field of view of $\sim 20$ microns, and imaging was performed by scanning the illumination lightsheet synchronously in the Z-direction with the piezo mounted detection objective.

Samples were imaged in phenol red free DMEM containing 25mM HEPES (ThermoFisher) with $10 \%$ FBS and antibiotic-antimycotic (Gibco), held at $37^{\circ} \mathrm{C}$ during imaging. Images were collected using sCMOS cameras (Orca Flash4.0 v2, Hamamatsu) and the microscopes were operated using custom Labview software. All software was developed using a 64-bit version of LabView 2016 equipped with the LabView Run-Time Engine, Vision Development Module, Vision Run-Time Module and all appropriate device drivers, including NI-RIO Drivers (National Instruments). The software communicated with the camera via the DCAM-API for the Active Silicon Firebird frame-grabber and delivered a series of deterministic TTL triggers with a field programmable gate array (PCle 7852R, National Instruments). These triggers included analog outputs for control of mirror galvanometers, piezoelectric actuators, laser modulation and blanking, camera fire and external trigger. All 
images were saved in the OME-TIFF format. The microscope control software is freely available to academic and nonprofit institutions upon completion of a material transfer agreement with the University of Texas Southwestern Medical Center.

\section{D Cell Image Analysis}

Cell morphology and septin localization were analyzed principally via u-shape3D ${ }^{31}$. Briefly, 3D images were first deconvolved using either a Richardson-Lucy or Wiener algorithm with an experimentally measured point spread function. Cells were next segmented from the image background using u-shape3D's 'twoLevel' mode, which combines a straightforward Otsu threshold ${ }^{84}$ of the image to detect the outer cell surface with a blurred version of the image to segment the inside of the cell. The volume segmented from the blurred image was morphologically eroded to ensure the fidelity of the overall segmentation. Cell surfaces were then represented as triangle meshes, and the mean surface curvature at every triangle was calculated as previously described ${ }^{31,54}$. To remove irregularities, the curvature is next smoothed in real space with a median filter of 1 pixel to remove infinities and then slightly diffused along the mesh.

Septin and NRAS localization was measured from fluorescence images by extending a sphere of either $1 \mu \mathrm{m}$ (for septins) or $2 \mu \mathrm{m}$ (for NRAS) about each mesh triangle and mapping to the triangle the average intensity both within that sphere and the cell. Unlike in previous studies ${ }^{31,54}$ the image intensity was not depth normalized prior to analysis, but was instead measured from the raw, undeconvolved image. To measure the localization of septin structures, rather than total septin, in figures $2 \mathrm{C}$ and $2 \mathrm{E}$ we employed a previously published multiscale stochastic filter to enhance dot-like structures ${ }^{85}$. With this filter, we used scales of 2 to 4 pixels, and an $\mathrm{a}=0.01$.

Blebs were also detected as previously described ${ }^{31}$. Machine learning models trained via images labeled by three separate expert annotators were combined via voting to classify blebs. Distances from bleb edges were then calculated as the geodesic distance from each triangle to the nearest bleb edge. The blebby surface fraction was also defined as the percentage of total mesh triangles classified as on a bleb. Bleb and septin directional correlations were calculated using spherical statistics ${ }^{31}$, in particular by fitting spherical normal distributions to distributions defined at each mesh triangle.

Cortical septin levels were quantified by measuring the mean cytoplasmic intensity of each cell using handdrawn ROls that excluded nuclei, and then calculating for each cell its fraction of cortical voxels (intracellular voxels within $0.96 \mu \mathrm{m}$ of the u-Shape3D-derived surface) that were higher than that cell's mean cytoplasmic intensity. NRAS enrichment at the surface was quantified by first calculating the total amount of intracellular signal expected to be within $0.96 \mu \mathrm{m}$ of the surface if the cell's signal was homogenously distributed between all voxels, and then calculating the percent change between this value and the observed value for each cell. To quantify PI3K biosensor fluorescence signal, cells were segmented with u-shape3D and the intracellular signal was summed across the z-axis to yield a sum projection image. To account for differential biosensor expression levels, projections were normalized by adjusting brightness until the mean cytoplasmic signals of all images were approximately the same. PI3K activity was then quantified as the fraction of total pixels with shades brighter than a threshold value (the approximate upper range of cytoplasmic signal), which was held constant across cells.

To quantify NRAS distributions, Earth Mover's Distance (EMD) was measured on discrete surfaces ${ }^{64}$. For a single cell, the measured intensity of NRAS-GFP signal at the surface was modified in two steps to compensate for cell-to-cell variations in fluorescence intensity. First, because we were interested only in bright areas representing high NRAS density, a surface background defined as the median of surface intensity was subtracted from the measured surface intensity, and the resulting values were divided by the mean cytoplasmic intensity derived manually as previously described. Resulting negative intensity values along the triangle mesh surface were set to zero. For each cell, EMD measured the distance between the modified NRAS signal distribution on each cell surface and homogenous distributions of the same amount of signal on the same surface. 


\section{Visualization and Statistics}

3D surface renderings were made in ChimeraX ${ }^{86}$. Colored triangle meshes representing the cell surface were imported into ChimeraX from u-shape3D as Collada dae files, as previously described ${ }^{31}$. The FIJI ImageJ package (https://imagej.net/Fiii) was used to prepare MIP and slice images. High-speed 3D light-sheet imaging movies were made using Arivis4D. All other figures were prepared using the Seaborn ${ }^{87}$ and Matplotlib ${ }^{88}$ Python visualization libraries, and the pandas ${ }^{89,90}$ Python data analysis library. Figures were assembled using the InkScape (https://inkscape.org/) vector graphics editor. Significance tests were performed using either two sample T-tests with pooled variance, Welch's T-tests, or Mann-Whitney $U$ tests, depending on whether datasets had normal distributions (as measured by Shapiro-Wilk tests) and equal variance (as measured by Ftests). Statistical calculations were performed using R for Windows, 4.0 .5 (https://www.r-project.org/). Error bars in figures show $95 \%$ confidence intervals. Number of cells and/or number of different experiments analyzed are given in the figure legends and in Table 1.

\section{Acknowledgements}

We would like to thank John Huang of TheWell Bioscience for providing information about the physical properties of VitroGel, Dagan Segal for discussions about septin inhibition, Xuexia Jiang for conversations about optimal transport, Vasanth Murali for assistance in designing viability experiments, Philippe Roudot for conversations on 3D image analysis, and Michael McMurray for helpful discussion of the manuscript. Funding for this work in the Danuser lab has been provided through grants R35 GM136428 (NIH) and I-1840-20200401 (Welch Foundation). Andrew Weems is a fellow of the Jane Coffin Childs Memorial Fund.

\section{References}

1. Frisch, S. M. \& Francis, H. Disruption of epithelial cell-matrix interactions induces apoptosis. J. Cell Biol. 124, 619-626 (1994).

2. Mori, S. et al. Anchorage-independent cell growth signature identifies tumors with metastatic potential. Oncogene 28, 2796-2805 (2009).

3. Guadamillas, M. C., Cerezo, A. \& del Pozo, M. A. Overcoming anoikis - pathways to anchorageindependent growth in cancer. Journal of Cell Science vol. 124 3189-3197 (2011).

4. Shin, S. I., Freedman, V. H., Risser, R. \& Pollack, R. Tumorigenicity of virus transformed cells in nude mice is correlated specifically with anchorage independent growth in vitro. Proc. Natl. Acad. Sci. U. S. A. 72, 4435-4439 (1975).

5. Paoli, P., Giannoni, E. \& Chiarugi, P. Anoikis molecular pathways and its role in cancer progression. Biochimica et Biophysica Acta - Molecular Cell Research vol. 1833 3481-3498 (2013).

6. Charras, G. T., Coughlin, M., Mitchison, T. J. \& Mahadevan, L. Life and times of a cellular bleb. Biophys. J. 94, 1836-1853 (2008).

7. Zollinger, H. U. Cytologic studies with the phase Microscope; the formation of blisters on cells in suspension, photocytosis, with observations on the nature of the cellular membrane. Am. J. Pathol. 24, 545-67 (1948).

8. Höglund, A. S. The arrangement of microfilaments and microtubules in the periphery of spreading fibroblasts and glial cells. Tissue Cell 17, 649-666 (1985). 
bioRxiv preprint doi: https://doi.org/10.1101/2021.04.23.441200; this version posted April 24, 2021. The copyright holder for this preprint (which was not certified by peer review) is the author/funder, who has granted bioRxiv a license to display the preprint in perpetuity. It is made available under aCC-BY-NC-ND 4.0 International license.

9. Ruprecht, V. et al. Cortical contractility triggers a stochastic switch to fast amoeboid cell motility. Cell 160, 673-685 (2015).

10. Bereiter-Hahn, J., Luck, M., Mdebach, T., Stelzer, H. K. \& Voth, M. Spreading of trypsinized cells: cytoskeletal dynamics and energy requirements. (1990).

11. Garnett, H. M. A scanning electron microscope study of the sequential changes in morphology occurring in human fibroblasts placed in suspension culture. Cytobios 27, 7-18 (1980).

12. Kinn, S. R. \& Allen, T. D. Conversion of Blebs to Microvilli: Cell Surface Reorganisation After Trypsin. Differentiation 20, 168-173 (1981).

13. Rovensky, Y. A. \& Vasiliev, J. M. Surface Topography of Suspended Tissue Cells. Int. Rev. Cytol. 90, 273-307 (1984).

14. Welf, E. S. et al. Worrying drives cell migration in mechanically unrestrained environments. doi:10.1101/2020.11.09.372912.

15. Guzman, A., Avard, R. C., Devanny, A. J., Kweon, O. S. \& Kaufman, L. J. Delineating the role of membrane blebs in a hybrid mode of cancer cell invasion in three-dimensional environments. J. Cell Sci. 133, (2020).

16. Cantelli, G. et al. TGF- $\beta$-Induced Transcription Sustains Amoeboid Melanoma Migration and Dissemination. Curr. Biol. 25, 2899-2914 (2015).

17. Tozluoğlu, M. et al. Matrix geometry determines optimal cancer cell migration strategy and modulates response to interventions. Nat. Cell Biol. 15, 751-762 (2013).

18. Sanz-Moreno, V. et al. ROCK and JAK1 Signaling Cooperate to Control Actomyosin Contractility in Tumor Cells and Stroma. Cancer Cell 20, 229-245 (2011).

19. Orgaz, J. L. et al. Diverse matrix metalloproteinase functions regulate cancer amoeboid migration. Nat. Commun. 5, 1-13 (2014).

20. Kanchanawong, P. et al. Nanoscale architecture of integrin-based cell adhesions. Nature 468, 580-584 (2010).

21. Frisch, S. M., Vuori, K., Ruoslahti, E. \& Chan-Hui, P. Y. Control of adhesion-dependent cell survival by focal adhesion kinase. J. Cell Biol. 134, 793-799 (1996).

22. Niessen, C. M. \& Gottardi, C. J. Molecular components of the adherens junction. Biochimica et Biophysica Acta - Biomembranes vol. 1778 562-571 (2008).

23. Hofmann, C. et al. Cell-Cell Contacts Prevent Anoikis in Primary Human Colonic Epithelial Cells. Gastroenterology 132, 587-600 (2007).

24. Lugo, H., Faussat, A.-M. \& Renaud, F. Early Loss of E-cadherin from Cell-Cell Contacts Is Involved in the Onset of Anoikis in Enterocytes Role of AhR, a transcription factor, and lipids on intestinal barrier dysfunctions View project Evaluation of total body water View project Stéphane Fouque. Artic. J. Biol. Chem. (2004) doi:10.1074/jbc.M405095200.

25. Horton, E. R. et al. Definition of a consensus integrin adhesome and its dynamics during adhesion complex assembly and disassembly. Nat. Cell Biol. 17, 1577-1587 (2015).

26. Aoki, K. et al. Coordinated changes in cell membrane and cytoplasm during maturation of apoptotic bleb. Mol. Biol. Cell 31, 833-844 (2020).

27. Zhang, Y., Chen, X., Gueydan, C. \& Han, J. Plasma membrane changes during programmed cell deaths. Cell Research vol. 28 9-21 (2018).

28. Keller, H., Rentsch, P. \& Hagmann, J. Differences in cortical actin structure and dynamics document that different types of blebs are formed by distinct mechanisms. Exp. Cell Res. 277, 161-172 (2002). 
bioRxiv preprint doi: https://doi.org/10.1101/2021.04.23.441200; this version posted April 24, 2021. The copyright holder for this preprint (which was not certified by peer review) is the author/funder, who has granted bioRxiv a license to display the preprint in perpetuity. It is made available under aCC-BY-NC-ND 4.0 International license.

29. Norman, L. L., Bruges, J., Sengupta, K., Sens, P. \& Aranda-Espinoza, H. Cell blebbing and membrane area homeostasis in spreading and retracting cells. Biophys. J. 99, 1726-1733 (2010).

30. Khan, Z. S., Santos, J. M., Vaz, N. G. \& Hussain, F. Enhanced blebbing as a marker for metastatic prostate cancer. Biomicrofluidics 13, 034110 (2019).

31. Driscoll, M. K. et al. Robust and automated detection of subcellular morphological motifs in 3D microscopy images. Nat. Methods doi:10.1038/s41592-019-0539-z.

32. Moes, M. J. A., Bijvelt, J. J. \& Boonstra, J. Attachment of HeLa cells during early G1 phase. Histochem. Cell Biol. 136, 399-411 (2011).

33. van Muijen, G. N. P. et al. Establishment and characterization of a human melanoma cell line (MV3) which is highly metastatic in nude mice. Int. J. Cancer 48, 85-91 (2007).

34. Giard, D. J. et al. In Vitro Cultivation of Human Tumors: Establishment of Cell Lines Derived From a Series of Solid Tumors2. JNCI J. Natl. Cancer Inst. 51, 1417-1423 (1973).

35. Quintana, E. et al. Human melanoma metastasis in NSG mice correlates with clinical outcome in patients. Sci. Transl. Med. 4, 159ra149-159ra149 (2012).

36. Huang, J. 3D Cell Culture On VitroGel System. Cytol. Tissue Biol. 6, 1-10 (2019).

37. Cannon, K. S., Woods, B. L., Crutchley, J. M. \& Gladfelter, A. S. An amphipathic helix enables septins to sense micrometer-scale membrane curvature. J. Cell Biol. 218, 1128-1137 (2019).

38. Bridges, A. A., Jentzsch, M. S., Oakes, P. W., Occhipinti, P. \& Gladfelter, A. S. Micron-scale plasma membrane curvature is recognized by the septin cytoskeleton. J. Cell Biol. 213, 23-32 (2016).

39. Gilden, J. K., Peck, S., Chen, Y. C. M. \& Krummel, M. F. The septin cytoskeleton facilitates membrane retraction during motility and blebbing. J. Cell Biol. 196, 103-114 (2012).

40. Østevold, K. et al. Septin remodeling is essential for the formation of cell membrane protrusions (microtentacles) in detached tumor cells. Oncotarget 8, 76686-76698 (2017).

41. Kinoshita, M. Diversity of septin scaffolds. Current Opinion in Cell Biology vol. 18 54-60 (2006).

42. Oh, Y. \& Bi, E. Septin structure and function in yeast and beyond. Trends in Cell Biology vol. 21 141148 (2011).

43. Dolat, L., Hu, Q. \& Spiliotis, E. T. Septin functions in organ system physiology and pathology. Biological Chemistry vol. 395 123-141 (2014).

44. Neubauer, K. \& Zieger, B. The Mammalian Septin Interactome. Front. Cell Dev. Biol. 5, 3 (2017).

45. Amir, S., Wang, R., Simons, J. W. \& Mabjeesh, N. J. SEPT9_v1 up-regulates hypoxia-inducible factor 1 by preventing its RACK1-mediated degradation. J. Biol. Chem. 284, 11142-11151 (2009).

46. Vardi-Oknin, D., Golan, M. \& Mabjeesh, N. J. Forchlorfenuron Disrupts SEPT9_i1 Filaments and Inhibits HIF-1. PLoS One 8, e73179 (2013).

47. Tazat, K., Schindler, S., Depping, R. \& Mabjeesh, N. J. Septin 9 isoform 1 (SEPT9_i1) specifically interacts with importin- $\alpha 7$ to drive hypoxia-inducible factor (HIF)-1a nuclear translocation. Cytoskeleton 76, 123-130 (2019).

48. Diesenberg, K., Beerbaum, M., Fink, U., Schmieder, P. \& Krauss, M. SEPT9 negatively regulates ubiquitin-dependent downregulation of EGFR. J. Cell Sci. 128, 397-407 (2015).

49. Mostowy, S. et al. A role for septins in the interaction between the Listeria monocytogenes invasion protein InIB and the Met receptor. Biophys. J. 100, 1949-1959 (2011).

50. Mostowy, S. et al. Septin 11 restricts InIB-mediated invasion by Listeria. J. Biol. Chem. 284, 11613- 
11621 (2009).

51. Gonzalez, M. E., Makarova, O., Peterson, E. A., Privette, L. M. \& Petty, E. M. Up-regulation of SEPT9_v1 stabilizes c-Jun-N-Terminal kinase and contributes to its pro-proliferative activity in mammary epithelial cells. Cell. Signal. 21, 477-487 (2009).

52. Marcus, E. A. et al. Septin oligomerization regulates persistent expression of ErbB2/HER2 in gastric cancer cells. Biochem. J. 473, 1703-1718 (2016).

53. Welf, E. S. et al. Quantitative Multiscale Cell Imaging in Controlled 3D Microenvironments. Dev. Cell 36, 462-475 (2016).

54. Elliott, H. et al. Myosin II controls cellular branching morphogenesis and migration in three dimensions by minimizing cell-surface curvature. Nat. Cell Biol. 17, 137-147 (2015).

55. Hu, Q., Nelson, W. J. \& Spiliotis, E. T. Forchlorfenuron alters mammalian septin assembly, organization, and dynamics. J. Biol. Chem. 283, 29563-29571 (2008).

56. Kim, D. I. et al. An improved smaller biotin ligase for BiolD proximity labeling. Mol. Biol. Cell 27, 11881196 (2016).

57. Mishra, S., Ande, S. R. \& Nyomba, B. L. G. The role of prohibitin in cell signaling. FEBS Journal vol. 277 3937-3946 (2010).

58. Freeman, A. K. \& Morrison, D. K. 14-3-3 Proteins: Diverse functions in cell proliferation and cancer progression. Seminars in Cell and Developmental Biology vol. 22 681-687 (2011).

59. Wu, D. M. et al. Phosphorylation and changes in the distribution of nucleolin promote tumor metastasis via the PI3K/Akt pathway in colorectal carcinoma. FEBS Lett. 588, 1921-1929 (2014).

60. Farin, K. et al. Oncogenic synergism between ErbB1, nucleolin, and mutant ras. Cancer Res. 71, 21402151 (2011).

61. Bowen, J. R., Hwang, D., Bai, X., Roy, D. \& Spiliotis, E. T. Septin GTPases spatially guide microtubule organization and plus end dynamics in polarizing epithelia. J. Cell Biol. 194, 187-197 (2011).

62. Sirajuddin, M., Farkasovsky, M., Zent, E. \& Wittinghofer, A. GTP-induced conformational changes in septins and implications for function. Proc. Natl. Acad. Sci. U. S. A. 106, 16592-16597 (2009).

63. Monge, G. Mémoire sur la théorie des déblais et des remblais. in Mémoires de l'Académie royale des sciences de Paris 666-704 (1781).

64. Solomon, J., Rustamov, R., Guibas, L. \& Butscher, A. Earth mover's distances on discrete surfaces. in ACM Transactions on Graphics vol. 33 1-12 (Association for Computing Machinery, 2014).

65. Nassar, N., Singh, K. \& Garcia-Diaz, M. Structure of the dominant negative S17N mutant of Ras. Biochemistry 49, 1970-1974 (2010).

66. de la Cova, C., Townley, R., Regot, S. \& Greenwald, I. A Real-Time Biosensor for ERK Activity Reveals Signaling Dynamics during C. elegans Cell Fate Specification. Dev. Cell 42, 542-553.e4 (2017).

67. Bridges, A. A. et al. Septin assemblies form by diffusion-driven annealing on membranes. Proc. Natl. Acad. Sci. U. S. A. 111, 2146-2151 (2014).

68. Meurette, O. et al. Notch activation induces Akt signaling via an autocrine loop to prevent apoptosis in breast epithelial cells. Cancer Res. 69, 5015-5022 (2009).

69. Teramoto, H. et al. Autocrine activation of an osteopontin-CD44-Rac pathway enhances invasion and transformation by H-RasV12. Oncogene 24, 489-501 (2005).

70. De Belly, H. et al. Membrane Tension Gates ERK-Mediated Regulation of Pluripotent Cell Fate. Cell Stem Cell (2020) doi:10.1016/j.stem.2020.10.018. 
bioRxiv preprint doi: https://doi.org/10.1101/2021.04.23.441200; this version posted April 24, 2021. The copyright holder for this preprint (which was not certified by peer review) is the author/funder, who has granted bioRxiv a license to display the preprint in perpetuity. It is made available under aCC-BY-NC-ND 4.0 International license.

71. Bergert, M. et al. Cell Surface Mechanics Gate Embryonic Stem Cell Differentiation. Cell Stem Cell (2020) doi:10.1016/j.stem.2020.10.017.

72. Otto, A., Collins-Hooper, H., Patel, A., Dash, P. R. \& Patel, K. Adult skeletal muscle stem cell migration is mediated by a blebbing/amoeboid mechanism. Rejuvenation Res. 14, 249-260 (2011).

73. Teo, G. S. L. et al. Mesenchymal stem cells transmigrate between and directly through tumor necrosis factor- $\alpha$-activated endothelial cells via both leukocyte-like and novel mechanisms. Stem Cells 30, 24722486 (2012).

74. Charras, G. \& Paluch, E. Blebs lead the way: How to migrate without lamellipodia. Nature Reviews Molecular Cell Biology vol. 9 730-736 (2008).

75. Paluch, E. K. \& Raz, E. The role and regulation of blebs in cell migration. Current Opinion in Cell Biology vol. 25 582-590 (2013).

76. Sedzinski, J. et al. Polar actomyosin contractility destabilizes the position of the cytokinetic furrow. Nature 476, 462-468 (2011).

77. Khajah, M. A. \& Luqmani, Y. A. Involvement of Membrane Blebbing in Immunological Disorders and Cancer. Med. Princ. Pract. 25, 18-27 (2016).

78. Zhou, Y. \& Hancock, J. F. Ras nanoclusters: Versatile lipid-based signaling platforms. Biochimica et Biophysica Acta - Molecular Cell Research vol. 1853 841-849 (2015).

79. Yakovian, O. et al. MEK Inhibition Reverses Aberrant Signaling in Melanoma Cells through Reorganization of NRas and BRAF in Self Nanoclusters. (2021) doi:10.1158/0008-5472.CAN-20-1205.

80. Muñoz-Couselo, E., Adelantado, E. Z., Ortiz, C., García, J. S. \& Perez-Garcia, J. NRAS-mutant melanoma: Current challenges and future prospect. OncoTargets and Therapy vol. 10 3941-3947 (2017).

81. Shurer, C. R. et al. Physical Principles of Membrane Shape Regulation by the Glycocalyx. Cell 177, 1757-1770.e21 (2019).

82. Dean, K. M., Roudot, P., Welf, E. S., Danuser, G. \& Fiolka, R. Deconvolution-free Subcellular Imaging with Axially Swept Light Sheet Microscopy. Biophys. J. 108, 2807-2815 (2015).

83. Dean, K. M. et al. Diagonally Scanned Light-Sheet Microscopy for Fast Volumetric Imaging of Adherent Cells. Biophys. J. 110, 1456-1465 (2016).

84. Otsu, N. A threshold selection method from gray-level histograms. Transactions on Systems, Man, and Cybernetics https://cw.felk.cvut.cz/lib/exe/fetch.php/courses/a6m33bio/otsu.pdf (1979).

85. Roudot, P. et al. U-track 3D: Measuring and interrogating intracellular dynamics in three dimensions. bioRxiv 2020.11.30.404814 (2020) doi:10.1101/2020.11.30.404814.

86. Goddard, T. D. et al. TOOLS FOR PROTEIN SCIENCE UCSF ChimeraX: Meeting modern challenges in visualization and analysis. (2017) doi:10.1002/pro.3235.

87. Waskom, M. seaborn: statistical data visualization. J. Open Source Softw. 6, 3021 (2021).

88. Hunter, J. D. Matplotlib: A 2D graphics environment. Comput. Sci. Eng. 9, 90-95 (2007).

89. Reback, J. et al. pandas-dev/pandas: Pandas 1.2.4. (2021) doi:10.5281/ZENODO.4681666.

90. McKinney, W. Data Structures for Statistical Computing in Python. in Proceedings of the 9th Python in Science Conference 56-61 (SciPy, 2010). doi:10.25080/majora-92bf1922-00a. 
bioRxiv preprint doi: https://doi.org/10.1101/2021.04.23.441200; this version posted April 24, 2021. The copyright holder for this preprint (which was not certified by peer review) is the author/funder, who has granted bioRxiv a license to display the preprint in perpetuity. It is made available under aCC-BY-NC-ND 4.0 International license.

Table 1 - Cell counts for pertinent experiments

\begin{tabular}{|c|c|c|c|c|c|c|c|c|}
\hline Figure 1B & $\begin{array}{l}\text { MV3 } \\
\text { Detached }\end{array}$ & $\begin{array}{l}\text { MV3 } \\
\text { Adhered }\end{array}$ & $\begin{array}{l}\text { M498 } \\
\text { Detached }\end{array}$ & $\begin{array}{l}\text { M498 } \\
\text { Adhered }\end{array}$ & $\begin{array}{l}\text { Unstressed } \\
\text { A375 } \\
\text { Detached }\end{array}$ & $\begin{array}{l}\text { Unstressed } \\
\text { A375 } \\
\text { Adhered }\end{array}$ & $\begin{array}{l}\text { Prestressed } \\
\text { A375 } \\
\text { Detached }\end{array}$ & $\begin{array}{l}\text { Prestressed } \\
\text { A375 } \\
\text { Adhered }\end{array}$ \\
\hline 0 WGA & 172 & 305 & 121 & 112 & 313 & 137 & 242 & 93 \\
\hline 2.5 WGA & 179 & 234 & 107 & 123 & 340 & 162 & 93 & 87 \\
\hline 5 WGA & 151 & 254 & 84 & 103 & 234 & 184 & 54 & 75 \\
\hline 10 WGA & 109 & 136 & 117 & 94 & 376 & 171 & 31 & 79 \\
\hline 20 WGA & 137 & 254 & 69 & 96 & 281 & 181 & 42 & 74 \\
\hline 0 WGA & 104 & 167 & 89 & 161 & 212 & 204 & 69 & 59 \\
\hline 2.5 WGA & 113 & 185 & 104 & 113 & 134 & 138 & 59 & 51 \\
\hline 5 WGA & 123 & 174 & 36 & 137 & 195 & 211 & 99 & 28 \\
\hline 10 WGA & 120 & 139 & 38 & 111 & 131 & 162 & 51 & 42 \\
\hline 20 WGA & 133 & 149 & 33 & 137 & 153 & 173 & 46 & 57 \\
\hline 0 WGA & 194 & 216 & 80 & 132 & 342 & 235 & 185 & 343 \\
\hline 2.5 WGA & 310 & 150 & 80 & 142 & 323 & 153 & 341 & 443 \\
\hline 5 WGA & 205 & 169 & 39 & 107 & 241 & 194 & 496 & 345 \\
\hline 10 WGA & 272 & 151 & 32 & 80 & 340 & 245 & 235 & 383 \\
\hline 20 WGA & 292 & 141 & 31 & 83 & 245 & 201 & 237 & 344 \\
\hline
\end{tabular}

\begin{tabular}{l|rrrr} 
& \multicolumn{1}{|l}{ MV3 } & \multicolumn{1}{l}{ MV3 } & A375 & \multicolumn{1}{l}{ A375 } \\
Figure 1D & Detached & Adhered & Detached & Adhered \\
\hline Rep 1 & 94 & 194 & 152 & 131 \\
Rep 2 & 87 & 114 & 113 & 132 \\
Rep 3 & 91 & 33 & 89 & 108 \\
Rep 4 & 95 & 48 & 107 & 138
\end{tabular}

\begin{tabular}{|c|c|c|c|c|c|c|c|c|}
\hline Figure 3B & $\begin{array}{l}\text { MV3 } \\
\text { Detached }\end{array}$ & $\begin{array}{l}\text { MV3 } \\
\text { Adhered }\end{array}$ & $\begin{array}{l}\text { M498 } \\
\text { Detached }\end{array}$ & $\begin{array}{l}\text { M498 } \\
\text { Adhered }\end{array}$ & $\begin{array}{l}\text { Unstressed } \\
\text { A375 } \\
\text { Detached }\end{array}$ & $\begin{array}{l}\text { Unstressed } \\
\text { A375 } \\
\text { Adhered }\end{array}$ & $\begin{array}{l}\text { Prestressed } \\
\text { A375 } \\
\text { Detached }\end{array}$ & $\begin{array}{l}\text { Prestressed } \\
\text { A375 } \\
\text { Adhered }\end{array}$ \\
\hline Experimental 1 & 170 & 241 & 81 & 111 & 277 & 184 & 345 & 66 \\
\hline Control 1 & 194 & 216 & 80 & 132 & 313 & 137 & 230 & 53 \\
\hline Experimental 2 & 133 & 149 & 100 & 132 & 205 & 156 & 39 & 70 \\
\hline Control 2 & 104 & 167 & 89 & 161 & 212 & 204 & 242 & 93 \\
\hline Experimental 3 & 137 & 254 & 117 & 95 & 341 & 222 & 34 & 33 \\
\hline Control 3 & 172 & 305 & 121 & 112 & 342 & 235 & 69 & 59 \\
\hline
\end{tabular}

\begin{tabular}{l|rr} 
& \multicolumn{1}{|l}{ MV3 } & \multicolumn{2}{l}{ MV3 } \\
Figure 4D & Detached & Adhered \\
\hline Experimental 1 & 279 & 256 \\
Control 1 & 453 & 253 \\
Experimental 2 & 388 & 281 \\
Control 2 & 349 & 246 \\
Experimental 3 & 438 & 262 \\
Control 3 & 237 & 235
\end{tabular}


bioRxiv preprint doi: https://doi.org/10.1101/2021.04.23.441200; this version posted April 24, 2021. The copyright holder for this preprint (which was not certified by peer review) is the author/funder, who has granted bioRxiv a license to display the preprint in perpetuity. It is made available under aCC-BY-NC-ND 4.0 International license.

\begin{tabular}{l|rr} 
Figure 4E & Control & FCF \\
\hline Adhered & 65 & 61 \\
Adhered & 48 & 59 \\
Adhered & 58 & 53 \\
Adhered & 63 & 63 \\
Detached & 236 & 164 \\
Detached & 212 & 149 \\
Detached & 350 & 258 \\
Detached & 252 & 278
\end{tabular}

\begin{tabular}{l|rr} 
Figure 4F & Adhered & Detached \\
\hline Control & 65 & 98 \\
Control & 67 & 73 \\
Control & 75 & 73 \\
Control & 69 & 50 \\
SEPT2(33-306) & 63 & 36 \\
SEPT2(33-306) & 33 & 46 \\
SEPT2(33-306) & 42 & 40 \\
SEPT2(33-306) & 69 & 42 \\
VitroGel & 61 & 84 \\
VitroGel & 56 & 64 \\
VitroGel & 55 & 63
\end{tabular}


bioRxiv preprint doi: https://doi.org/10.1101/2021.04.23.441200; this version posted April 24, 2021. The copyright holder for this preprint (which was not certified by peer review) is the author/funder, who has granted bioRxiv a license to display the preprint in perpetuity. It is made available under aCC-BY-NC-ND 4.0 International license.

Table 2 - Septin proteomic results

\begin{tabular}{|c|c|c|c|}
\hline Experiment & Septin & $\begin{array}{c}\% \text { of total septin } \\
\text { abundance } \\
\text { (fold change between } \\
\text { lysate and pulldown) }\end{array}$ & $\begin{array}{c}\% \text { of total protein abundance } \\
\text { (fold change between lysate } \\
\text { and pulldown) }\end{array}$ \\
\hline MV3 & SEPTIN2 & 19.99 & 0.04 \\
\hline \multirow[t]{8}{*}{ Lysate } & SEPTIN6 & 40.98 & 0.09 \\
\hline & SEPTIN7 & 8.80 & 0.02 \\
\hline & SEPTIN9 & 12.93 & 0.03 \\
\hline & SEPTIN8 & 0.31 & $<0.01$ \\
\hline & SEPTIN10 & 16.97 & 0.04 \\
\hline & SEPTIN11 & ND & ND \\
\hline & SEPTIN3 & ND & ND \\
\hline & All Septins & N/A & 0.22 \\
\hline MV3 & SEPTIN2 & $30.09(1.50)$ & $2.43(60.75)$ \\
\hline SEPT6-HALO & SEPTIN6 & $12.82(-3.20)$ & $1.03(11.44)$ \\
\hline \multirow[t]{7}{*}{ Pulldown } & SEPTIN7 & 29.88 (3.39) & $2.41(120.50)$ \\
\hline & SEPTIN9 & $22.97(1.78)$ & $1.85(61.67)$ \\
\hline & SEPTIN8 & $0.09(-3.44)$ & $<0.01(\mathrm{~N} / \mathrm{A})$ \\
\hline & SEPTIN10 & $3.19(-5.32)$ & $0.28(7)$ \\
\hline & SEPTIN11 & $0.94(\mathrm{~N} / \mathrm{A})$ & $0.08(N / A)$ \\
\hline & SEPTIN3 & $\mathrm{ND}(\mathrm{N} / \mathrm{A})$ & $\mathrm{ND}(\mathrm{N} / \mathrm{A})$ \\
\hline & All Septins & N/A & $8.06(35.86)$ \\
\hline A375 & SEPTIN2 & 26.42 & 0.03 \\
\hline \multirow[t]{8}{*}{ Lysate } & SEPTIN6 & 31.71 & 0.03 \\
\hline & SEPTIN7 & 15.60 & 0.02 \\
\hline & SEPTIN9 & 18.99 & 0.02 \\
\hline & SEPTIN8 & ND & ND \\
\hline & SEPTIN10 & 1.92 & $<0.01$ \\
\hline & SEPTIN11 & 5.36 & $<0.01$ \\
\hline & SEPTIN3 & ND & ND \\
\hline & All Septins & N/A & 0.12 \\
\hline A375 & SEPTIN2 & $25.71(-1.03)$ & $1.81(60.33)$ \\
\hline SEPT6-HALO & SEPTIN6 & $23.77(-1.33)$ & 1.67 (55.67) \\
\hline \multirow[t]{7}{*}{ Pulldown } & SEPTIN7 & $21.07(1.35)$ & $1.48(74)$ \\
\hline & SEPTIN9 & $22.08(1.62)$ & $1.55(77.5)$ \\
\hline & SEPTIN8 & $0.02(N / A)$ & $<0.01(\mathrm{~N} / \mathrm{A})$ \\
\hline & SEPTIN10 & $7.23(3.77)$ & $0.51(\mathrm{~N} / \mathrm{A})$ \\
\hline & SEPTIN11 & $0.12(-44.67)$ & $<0.01(\mathrm{~N} / \mathrm{A})$ \\
\hline & SEPTIN3 & $N D(N / A)$ & ND (N/A) \\
\hline & All Septins & N/A & 7.04 (56.02) \\
\hline
\end{tabular}


MV3
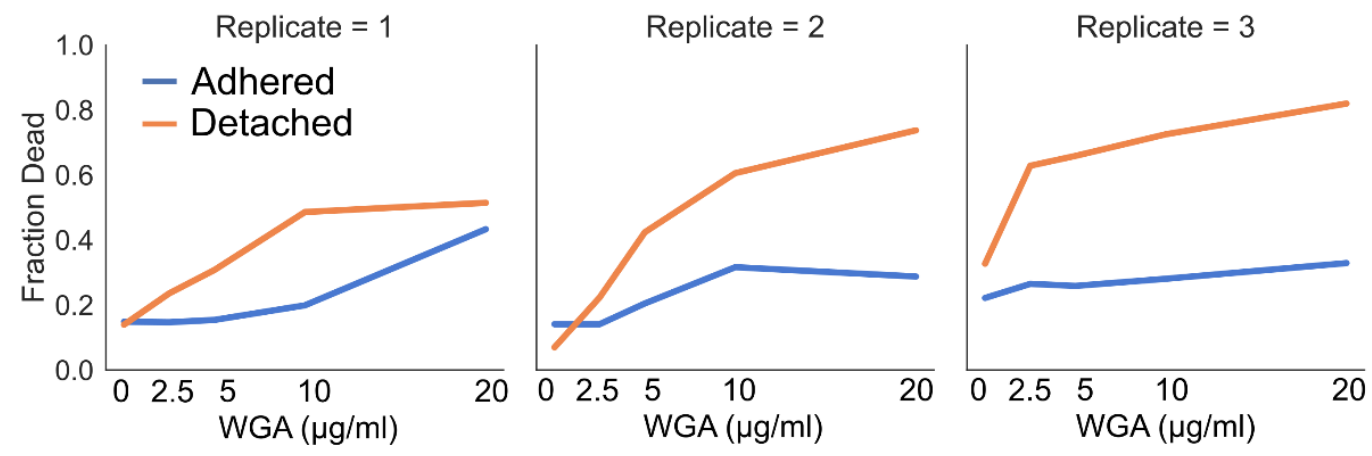

M498
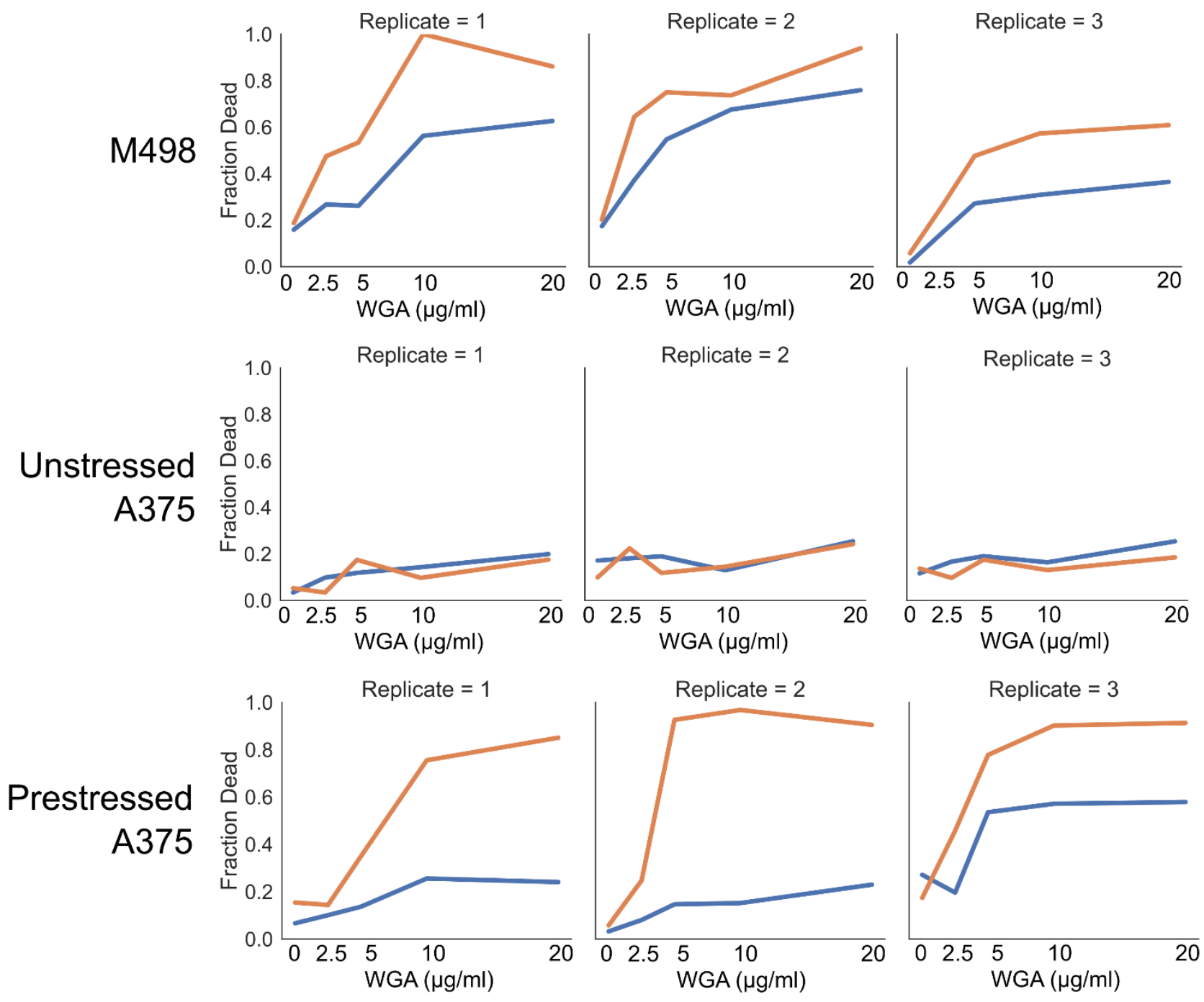

Figure S1: Individual bleb inhibition viability experiments. Individual bleb inhibition viability experiments, as summarized in Figure 1B. All paired adhered/detached experiments were performed on the same day and seeded with cells from the same diluted cell suspensions. 


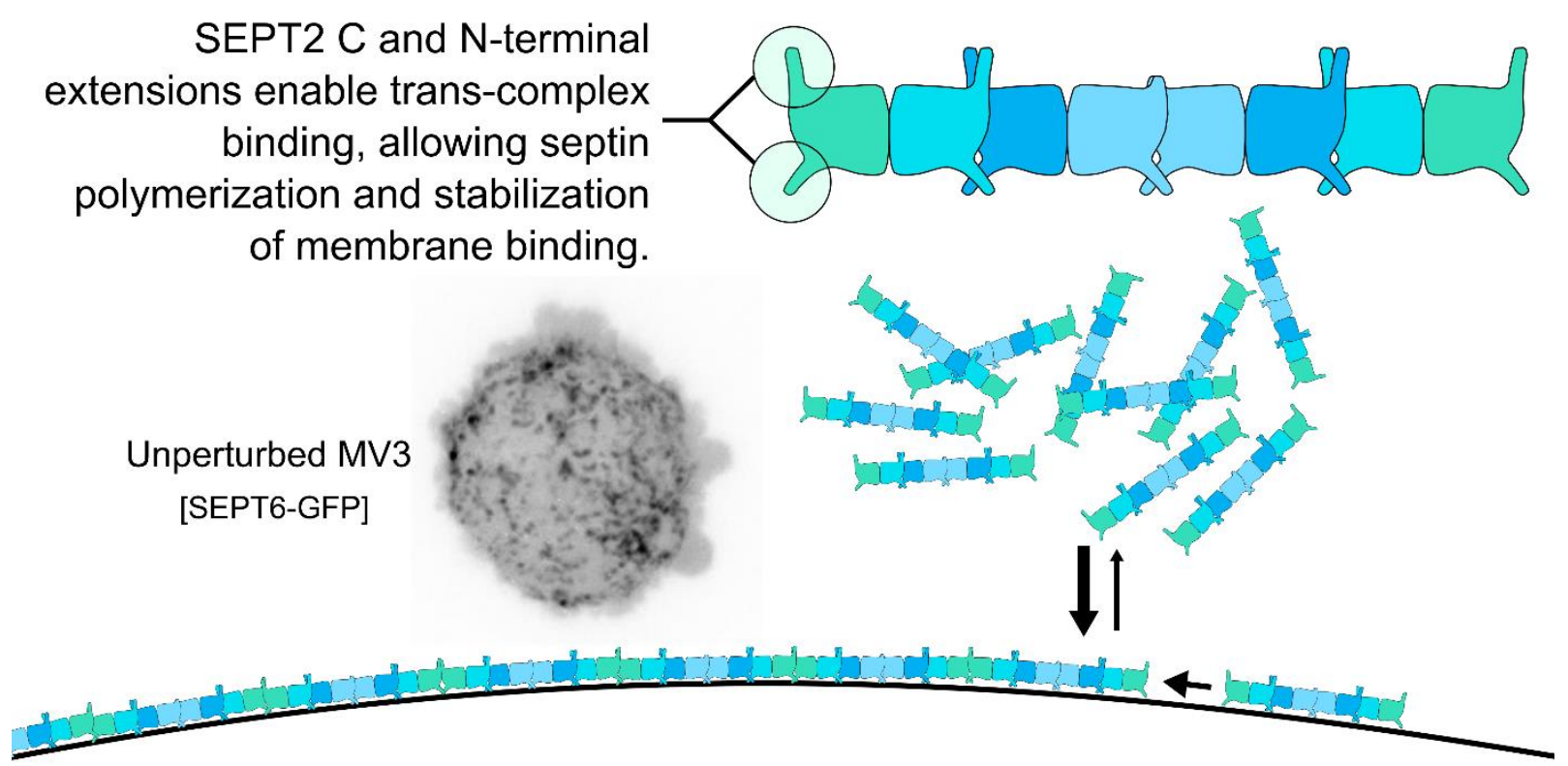

\section{SEPT2(33-306) lacks terminal extensions but is able to integrate into septin complexes, allowing dominant inhibition of polymerization and prevention of stable membrane binding}

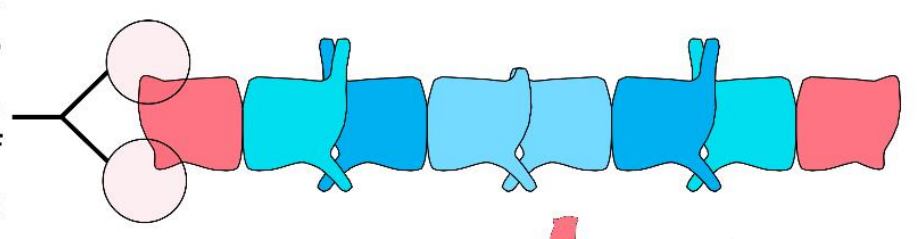

Septin polymerization inhibited MV3 [SEPT2(33-306), SEPT6-GFP]
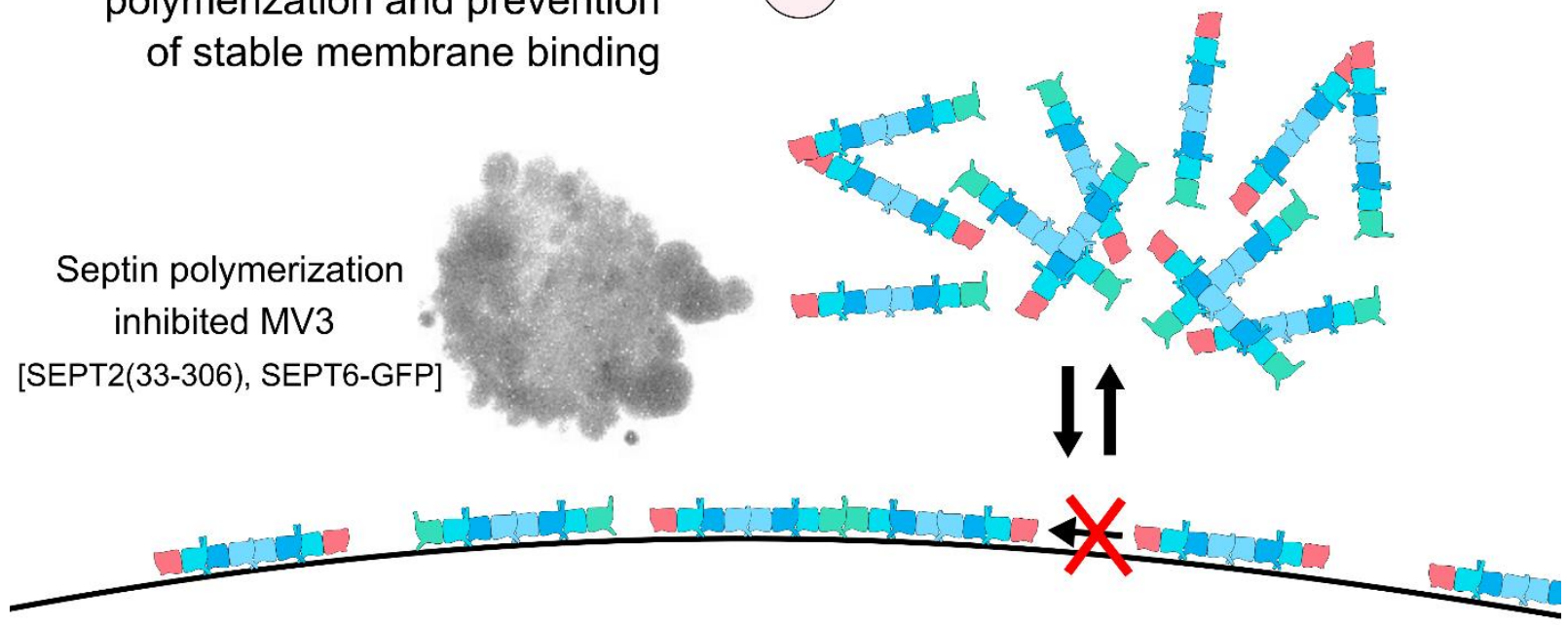

Figure S2: Explanation of SEPT2(33-306) mutant. Micrographs are maximum intensity z-projections of SEPT6-GFP carrying MV3 cells, without and with expression of the SEPT2(33-306) mutant. 

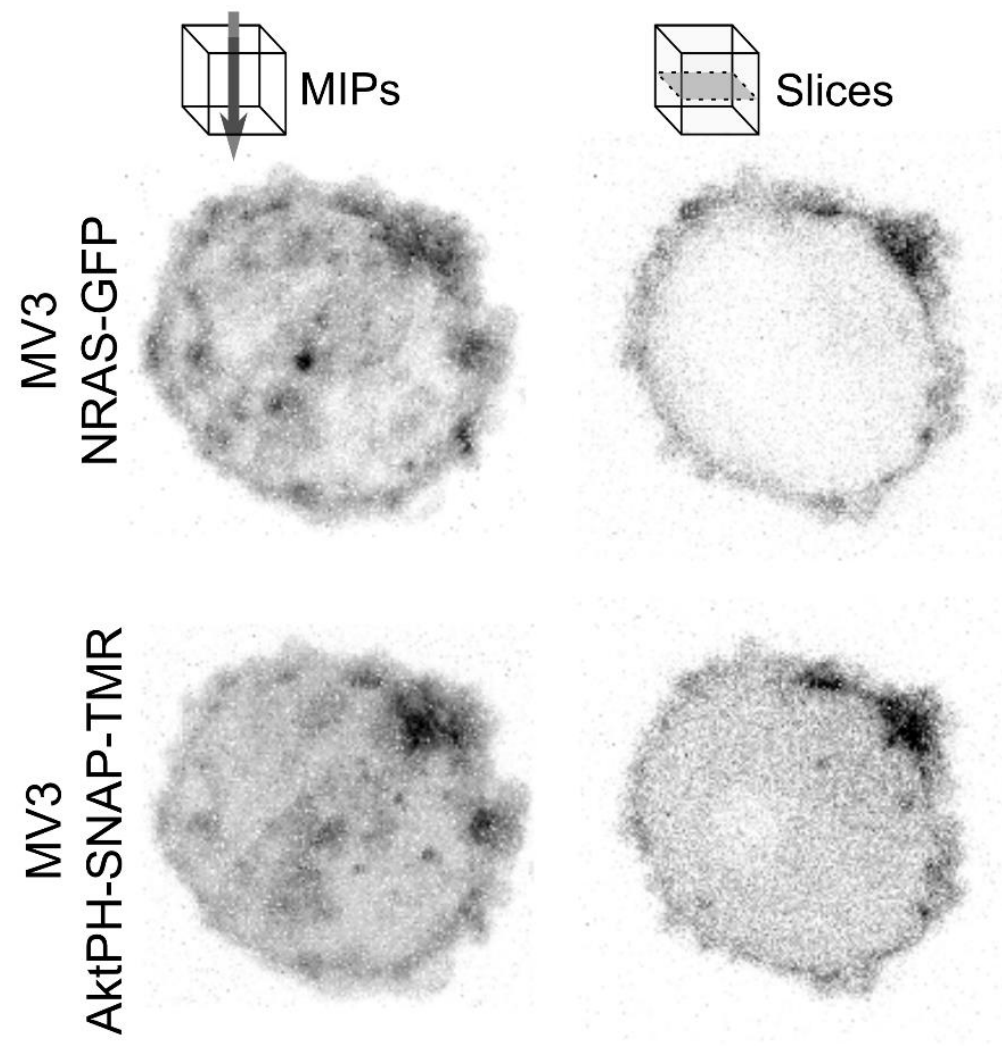

\section{Figure S3: Colocalization between NRAS and areas of increased}

PI3K activity. Micrographs are either maximum intensity projections or single slices of 0.16 micron thickness of the same MV3 cell. Top shows NRAS-GFP localization, bottom shows PI3K activity biosensor AktPHSNAP-TMR localization. 